In revision for Journal of Seismology, February 2018.

\title{
Mechanism of the $M\llcorner 4.0$ 25th April 2016 earthquake in southwest of France in the vicinity of the Lacq gas field
}

\author{
Hideo AOCHI and André BURNOL, BRGM \\ 3 avenue Claude Guillemin, BP36009 Orléans Cedex 2, France \\ Correponding author : H. Aochi ( h.aochi@brgm.fr )
}

\begin{abstract}
The source mechanism of the $M_{\llcorner} 4.025^{\text {th }}$ April 2016 Lacq earthquake (Aquitaine Basin, South-West France) is analyzed from the available public data and discussed with respect to the geometry of the nearby Lacq gas field. It is one of the biggest earthquakes in the area in the past few decades of gas extraction and the biggest after the end of gas exploitation in 2013. The routinely obtained location shows its hypocenter position inside the gas reservoir. We first analyze its focal mechanism through regional broad-band seismograms recorded in a radius of about $50 \mathrm{~km}$ epicentral distances and obtain EW running normal faulting above the reservoir. While the solution is stable using regional data only, we observe a large discrepancy between the recorded data on nearby station URDF and the forward modeling up to $1 \mathrm{~Hz}$. We then look for the best epicenter position through performing wave propagation simulations and constraining the potential source area by the Peak Ground Velocity (PGV). The resulting epicentral position is a few to several km away to the north or south direction with respect to station URDF such that the simulated particle motions are consistent with the observation. The initial motion of the seismograms shows that the epicenter position in the north from URDF is preferable, indicating the north-east of the Lacq reservoir. This study is an application of full waveform simulations and characterization of near-field ground motion in terms of an engineering factor such as PGV. The finally obtained solution gives a moment magnitude of Mw3.9 and the best focal depth of 4 $\mathrm{km}$, which corresponds to the crust above the reservoir rather than its interior. This position is consistent with the tendency of Coulomb stress change due to a compaction at $5 \mathrm{~km}$ depth in the crust. Therefore, this earthquake can be interpreted as a relaxation of the shallow crust due to a deeper gas reservoir compaction so that the occurrence of similar events cannot be excluded in the near future. It would be necessary to continue monitoring such local induced seismicity in order to better understanding the reservoir/overburden behavior and better assessing the local seismic hazard even after the end of gas exploitation.
\end{abstract}




\section{Introduction}

There were 11 earthquakes of magnitude larger than 3.8 in metropolitan France in 2016 according to the available catalogue EMSC (European-Mediterranean Seismological Centre). Among them, the $M\left\llcorner 4.025^{\text {th }}\right.$ April 2016 earthquake is suspected to be induced in gas exploitation field of Lacq, southwestern France, close to the Pyreneans mountains (Figure 1). Gas extraction in Lacq started in the late 1950's and ended in 2013. During the exploitation, the induced seismicity and crustal deformation has been intensively studied in the 1990's (e.g. Grasso and Wittlinger, 1990; Segall, 1992; Segall et al., 1994), and more recently summarized in Bardainne (2005) and Bardainne et al. (2008). Geophysical measurement of crustal deformation (subsidence) was explained by mechanical model of reservoir compaction (e.g. Segall, 1992). More than 2000 earthquakes have been recorded from 1974 to 1997 $\left(M_{L}<4.2\right)$ and the spatial patterns of the seismicity were correlated to the reservoir geometry and preexisting fault structure, principally orienting WNW-ESE direction (Bardainne et al., 2008). The $M_{\llcorner} 4.0$ 2016 earthquake is quite large comparing to the past seismicity in the area (Figure 1B), although the national catalogue summarized by Cara et al. (2015) may have removed recognized induced earthquakes from it. The seismicity shows that there are less large-magnitude events with time, while the increase in small events since mid-1990s probably reflects the improvement in the event detectability according to the network extension. This 2016 event was large enough to be perceived by local habitants and should be a scientific indicator in order to examine the current states of the crust and the reservoir of this old gas extraction field.

The efforts of the seismological observation have focused on the Pyrenean mountain range, about $30 \mathrm{~km}$ south from Lacq (Figure 1A), where French national broad-band and acceleration networks are deployed and the data are available from ORFEUS/EIDA (European Integrated Data Achieves). The M de Surveillance Sismique) at $\left(0.59^{\circ} \mathrm{W}, 43.44^{\circ} \mathrm{N}\right)$ and at $5 \mathrm{~km}$ depth. One broad-band station URDF (Urdes, $0.5931^{\circ} \mathrm{W}, 43.4383^{\circ} \mathrm{N}$ ) is located very closely to this epicenter only by a few hundred meters. Figure 2 shows examples of the available seismograms from the data archives. Note that all the stations other than URDF are at distances farther than $50 \mathrm{~km}$.

This earthquake is important to study, because the routinely obtained earthquake location corresponds to the inside of the reservoir of gas extraction field. In order to discuss possible relation to the reservoir and understand the underlying mechanism of this earthquake, we need to assess its source parameters. Therefore, we carry out the seismological analysis using available data. First, we will perform moment tensor inversion using very low frequencies from the regional data. The existence of the closest station URDF allows us to investigate the source parameters more precisely. Secondly, we will run ground motion simulations based on the obtained source mechanism. We will show that 
spatial distribution of Peak Ground Velocity (PGV) and particle motion patterns help constraining the possible earthquake location. This is the main purpose of this study; how to extract the useful information from one near-field ground motion data. Finally, for the obtained source parameters, we discuss the mechanical consistency through a calculation of Coulomb stress change due to a reservoir compaction.

\section{Regional moment tensor inversion}

\subsection{Analysis procedure}

The earthquake's location and magnitude are automatically obtained in the catalogue by RéNaSS. For our first purpose of obtaining the focal mechanism and a reliable focal depth, we carry out fullwaveform moment-tensor inversions using the regional data.

We fix the epicenter position obtained in the Rénass catalogue, namely at $\left(0.59^{\circ} \mathrm{W}, 43.44^{\circ} \mathrm{N}\right)$. We let the focal depth vary from 2 to $8 \mathrm{~km}$, compared to the $5 \mathrm{~km}$ depth provided in the Rénass catalogue. We use three stations at about $50 \mathrm{~km}$ distance from the epicenter and apply a band-pass filter between 16-32 seconds. This choice of source-receiver distances and frequency ranges are consistent with the operational moment-tensor inversion in other regions (e.g. Dreger and Helmberger, 1993; Kubo et al., 2002) and guarantees stable convergence. The Green's functions are calculated for each component of moment tensor in a regional 1D structure model (Souriau and Granet, 1995; Douglas et al., 2007), as presented in Figure 3. For simplicity, we use the angular fault parametrization (strike, dip and rake angles) instead of independent six components of the moment tensor. The model parameters to be obtained are moment magnitude $\left(\mathrm{M}_{\mathrm{w}}\right)$, origin time $\left(\mathrm{t}_{0}\right)$, fault strike, fault dip and fault rake for a given focal depth.

We apply a Genetic Algorithm (Holland, 1975; Goldberg, 1989) (GAUL library) to find the best combination of the model parameters. GA is suitable for multi-dimensional global search problems where the search space potentially contains multiple local minimum. GA shows a rapid convergence only after a few iterations of generation among several independent model parameters in earthquake source analyses (e.g. Ulrich and Aochi, 2015). As we use a very low frequency band, we extend the times series by padding with zero so as to use the time window from 20 seconds before the origin time (4h44:10 UTC, by Rénass) for duration of 60 seconds. The misfit function (residual) is defined in time domain as

$$
\text { misfit }=\sum_{\text {waveforms time }} \sum_{(s y n-o b s)^{2}}
$$


where syn and obs are the synthetic and observed signals of three components, respectively. The model parameters are searched such that misfit function is minimum.

\subsection{Result - Source mechanism}

The adopted GA algorithm shows a good convergence. Figure 4 shows the obtained focal mechanism for each focal depth from $2 \mathrm{~km}$ to $8 \mathrm{~km}$. Comparing to the routinely obtained focal depth of $5 \mathrm{~km}$, we obtain the minimum residual at $3 \mathrm{~km}$ depth. The residual is very stable from $2.5 \mathrm{~km}$ to 4 $\mathrm{km}$ depths. This relatively large depth range can be explained by a typical kilometric rupture length of a magnitude 4 earthquake. The result clearly shows that the event should be shallower than the one obtained by the routine location by one or two kilometers. The focal mechanism (strike, dip, rake) shows a EW-running normal fault, being $\left(78.1^{\circ}, 45.2^{\circ},-100.2^{\circ}\right)$ for $3 \mathrm{~km}$ depth location. On the other hand, the estimated moment magnitude ( $M$ w 3.8 ) is close to the routinely determined local magnitude of 4.0 .

Figures 5 and 6 show the convergence of the GA inversion and waveform comparison for the minimum residual (focal depth of $3 \mathrm{~km}$ ). It is found that the solution converges very quickly after about 10 generations. The GA sometimes attempts mutation process to maintain diversity (in mutation, a solution may change completely from the previous solution), but a better solution remains very stable around the final values. This reassures the reliability of the employed inversion process in this study.

One of the important purposes of this study is scrutinizing the ground motion in the near field where the populations felt this earthquake as reported in local media. Figure 7 compares the observations and synthetics at URDF in the same framework of the inversions, namely comparative to Figure 6. We show them for different focal depths. It is remarked that the obtained solution does not fit the observation at all, neither in its amplitude nor in phase. This discrepancy is because of the inadequate wave propagation in the near field probably due to the incorrect epicenter location, while the focal mechanism inversion is not bothered by this fact as the very low frequency band of the seismograms at distance (about $50 \mathrm{~km}$ ) is only analyzed.

\section{Near-field ground motion simulations and source parameters}

\subsection{Simulation Method}

For our second purpose of assessing the ground motion observed in the very near field (URDF), we carry out 3D numerical simulations of seismic wave propagation. We apply a 3D finite difference method (Aochi et al., 2013a,b). One can easily calculate the ground motion at one station using semianalytical methods such as discrete wavenumber method (Bouchon, 1981). However, as described 
later, we aim to explorer the ground motion pattern with respect to the source position. For calculating the ground motions at many receiver positions, the finite difference method is more convenient than discrete wave number method, as it is sufficient to run a single simulation once.

We limit our model dimension to a $15 \mathrm{~km}$ (EW) x $15 \mathrm{~km}$ (NS) x $12.5 \mathrm{~km}$ (depth) volume. The location of URDF is less than $1 \mathrm{~km}$ distance from the epicenter of Rénass. We discretize the volume with a $\Delta \mathrm{s}=$ $50 \mathrm{~m}$ spacing to have sufficient grids between source and receiver. The time step of finite difference simulation is taken as $\Delta t=0.003 \mathrm{~s}$, to satisfy the condition of stability and resolution for our interest. This discretization in finite difference scheme is fine enough to analyze the frequency range lower than $1 \mathrm{~Hz}$. The code is equipped with a Perfectly Matching Layer absorbing condition for minimizing artificial reflection from the outer boundaries (Collino and Tsogka, 2001). Earthquake source is introduced as a point source with a source time function of a cubic B-spline function of 0.5 -second duration (e.g. the same form of function given in Douglas et al., 2007). This function is suitable for simulating an earthquake of about magnitude 4 to characterize the low-frequency content of the signals (Aochi et al., 2013a). From engineering point of view of quantitative seismic hazard assessment, we calculate Peak Ground Velocity (PGV) from the calculated ground motion at each receiver, every $200 \mathrm{~m}$ around the hypocenter and every $500 \mathrm{~m}$ elsewhere after a low-pass filter of $1 \mathrm{~Hz}$. The use of synthetic PGV is more reliable than using any empirical attenuation relation (e.g. Battaglia and Aki, 2003) or Ground Motion Prediction Equations (GMPEs), which provides a measure of amplitude of signals (acceleration, velocity, spectra and so on) in function of magnitude and source-receiver distance without taking into account of complex seismic wave radiation in different azimuths.

\subsection{Result - source location}

Let us check the near-field ground motion at URDF in more detail. We ran a forward modeling supposing a detailed 1D structure model after Grasso and Wittlinger (1990) and Bardainne et al. (2008). The gas reservoir is in a 3D complex structure (low velocity zones at about $5 \mathrm{~km}$ and 7-8 km depths), which is not available digitally. However a local 1D structure model should be enough as epicentral distance to URDF is an order of $1 \mathrm{~km}$ and focal depth should be shallower than low velocity zones of the reservoir. The assumed 1D model is shown in Figure 8. The comparison of the ground motion for the best focal mechanism solution, namely Mw3.8 at $3 \mathrm{~km}$ depth, is shown in Figure 9 . The duration of the given source time function is supposed 0.5 seconds for a typical magnitude 4 event. The waveforms are filtered between 0.05 and $1 \mathrm{~Hz}$ so as to verify the onset of the ground motion. Indeed, the simulated ground motions do not fit very well the observation. The phases are shifted and the relative amplitudes of component are different. We also plot the particle motions of the first five seconds in panel (C). The simulation shows a large movement to the WSW-ENE direction corresponding to the azimuth toward the source position, while the observation indicates the $\mathrm{N}-\mathrm{S}$ direction. This test 
indicates that the direction where the wave comes from is different between the observation and the simulation and the source position may be incorrect.

Next we explore the ground motion patterns around the epicenter. We ran a simulation around the epicenter for many receivers (named internally from \#0001 to \#2041). Figure 10 shows the Peak Ground Velocity (the maximum value of ground velocity) for each component after a filter up to $1 \mathrm{~Hz}$. This indicates a very specific ground motion pattern due to the wave radiation from the source position. In order to estimate the epicenter position, we select the area only for PGV(NS)/PGV(EW) $>3$ and $0.043 \mathrm{~cm} / \mathrm{s}<P G V(N S)<0.387 \mathrm{~cm} / \mathrm{s}$ (a factor of 3 with respect to the observed value), noting that from Figure 9, PGV(NS)/PGV(EW) $=4.64$ and PGV(NS) $=0.129 \mathrm{~cm} / \mathrm{s}$ for the observation. This constrains the potential area of the epicenter location, which is probably to the North or South direction by a distance of 3 upto $10 \mathrm{~km}$ with respect to the station URDF. We calculate the misfit using the same definition as Equation (1), and this is shown in Figure 11. For the local minimum positions of the misfit (\#1249 in the North, and \#1196 in the South), we compare the waveforms in Figure 12. The horizontal particle motions are plotted for the first five seconds of the ground motions filtered between 0.02 and $1 \mathrm{~Hz}$. Both positions show the very similar particle motions dominating the North-South movements. Although the frequency band of simulations is still limited, we compare the beginning part of the NS ground motion without filtering to check the first motion direction (Figure 12C). The simulations for both receiver locations show an opposite sign of the ground motion. The observations are noisy and contain higher frequencies, but the displacement waveforms integrated once from the velocity show that the observation is rather consistent with the receiver \#1196, namely ground moves first to negative (southern) direction.

\subsection{Revisit of moment tensor inversion (final solution)}

Our preferred location of this earthquake is different from the one routinely obtained by a few kilometers. Although the regional moment tensor inversion at very low frequencies at distances of about $50 \mathrm{~km}$ (Chapter 2) should not be influenced significantly due to a small difference in epincenter, it is worth re-analyzing the solution for the new location. We carry out the same procedure as Chapter 2 and Figure 13 illustrates the solutions found for different focal depths. The best solution is found for Mw3.9 at 4 km depth (c.f. Mw3.8 at $3 \mathrm{~km}$ in Figure 4). The focal mechanism (strike, dip, rake) $=\left(66.3^{\circ}\right.$, $\left.32.0^{\circ},-114.6^{\circ}\right)$ is also consistent with the previous solution $\left(78.1^{\circ}, 45.2^{\circ},-100.2^{\circ}\right)($ Chapter 2$)$. This revisit justifies our analysis procedure and the obtained solution.

\subsection{Sensibility test}

Here we test the sensibility of the source description on the near-field ground motions. Magnitude 4 event briefly has a fault length $L$ of $1 \mathrm{~km}$, according to the empirical relation $L=$ 
$10^{-2.01+0.50 M}$ (Wells and Coppersmith, 1994). As there are still a few or several kilometers from source to receiver, a point source assumption is adopted in the previous calculation. However, any detail in source description might affect the ground motions, and then the spatial pattern of PGV. Here, we carry out ground motion simulations adopting stochastically simulated finite earthquake scenarios among the database of Ide and Aochi (2005). Figure 14 shows two tested earthquake scenarios. Ide and Aochi (2005) consider a heterogeneous fault model, stochastically generated through Fractal feature, and let rupture to propagate spontaneously according to the stress and the friction. The initiated rupture spontaneously progresses and stops. Among more than 15000 scenarios ranging from magnitudes M1.3 to M6, the selected two scenarios have moment magnitudes of 3.78 (Model A) and 3.83 (Model B), respectively. Two earthquakes have different rupture directivities (ruptured area with respect to the epicenter) and the duration of rupture is about 0.5 seconds.

Figure 15 shows the simulated PGV map for the two models. We assume the final focal mechanism, namely $\left(66.3^{\circ}, 32.0^{\circ},-114.6^{\circ}\right)$, by a difference of about $15^{\circ}$ in each angle comparing to the previous point source simulation (Figures 10 and 11). The spatial pattern changes particularly around the epicenter in the EW component due to the extension of the fault plane. However the NS component is still dominant in the ground motions. When we apply the same restriction on the PGV map as Figure 10, namely PGV(NS)/PGV(EW) $>3$ and $0.043 \mathrm{~cm} / \mathrm{s}<P G V(N S)<0.387 \mathrm{~cm} / \mathrm{s}$, we get almost the same area only by a slight difference of a few grids $(<2 \mathrm{~km})$. This test confirms the utilization of point source approximation in our approach and also shows the stability regardless of the uncertainty of source mechanism within about $15^{\circ}$. The point of interest is not located above the fault plane, but is at a horizontal distance of more than $5 \mathrm{~km}$. Thus the detail of the rupture process may not influence significantly on the ground motions, as the distance is several times larger than the fault dimension.

\section{Discussion}

We have studied a moderate earthquake precisely using regional networks. It is always better if local network was employed and made available; however, we have demonstrated that useful information can be extracted even from the limited data. In particular, the near-field ground motion recorded very closely to the epicenter allows us to calibrate the epicenter position through the PGV spatial distribution and particle motion. For the area of our study, there have been some other moderate earthquakes, such as the 2nd September 2013 (ML 4.0) and the 20th February 2017 (ML3.5) after Rénass report (see also Figure 1B). We have applied the same procedure of the analysis as in the 
previous chapter on these two earthquakes, using the same ATE, TERF and PYLO stations, though TERF did not record the 2013 event. The obtained focal mechanisms are summarized in Table 1. The moment magnitudes are estimated as Mw3.25 and 3.21, respectively, much smaller than the 2016 event. For the Mw3.25 2013/09/02 event, we show the detailed analysis in Appendix, as this earthquake could be important in terms of reported local magnitude (ML4.0) as large as the 2016 event. Near-field ground motion simulation upto $1 \mathrm{~Hz}$ confirms the small magnitude of Mw3.25. The localization is preferably estimated in the south-west by a few kilometers of station URDF, and this may correspond to the top of the reservoir.

Seismic network is costly. Another alternative is to collect the perception of habitants. Hough (2014) analyzed the felt data, corrected in USGS "Did you feel it?" system, for the recent moderate earthquakes ( $\mathrm{Mw}$ 4.0 - 5.6) occurring in the central and eastern US and obtained a regression equation to correlate the felt perception and the ground motions. For smaller magnitude events, for example, during a local seismicity crisis in a post-mining site in the South-Eastern France, Dominique (2016) calibrated the seismicity localization using felt reports to cope for the absence of instruments. His implication was confirmed later by using a local monitoring network. In our study, we used a factor of PGV (Peak Ground Velocity) for the estimate of epicenter position. PGV scale is often related to the felt perception. Bommer et al. (2006) proposed a notion such as "just perceptible" $(0.1 \mathrm{~cm} / \mathrm{s})$, "clearly perceptible" $(0.65 \mathrm{~cm} / \mathrm{s})$ and "disturbing" $(1.3 \mathrm{~cm} / \mathrm{s})$. The waveforms recorded at URDF peaked at 0.6 $\mathrm{cm} / \mathrm{s}$ (Figure 2), exceeding the $0.1 \mathrm{~cm} / \mathrm{s}$ threshold even after band-pass filtering between 0.05 and 1 $\mathrm{Hz}$ (Figure 9). This level is enough to call the perception of habitants. Furthermore, the simulation produces PGVs at around $0.4 \mathrm{~cm} / \mathrm{s}$ in the frequency range between 0.05 and $1 \mathrm{~Hz}$ (Figure 10), suggesting that PGV at full frequency ranges might have been large enough to reach locally the "disturbing" level of Bommer et al. (2006). Such perception is important in regions of moderate seismicity and should be quantified as a future task.

According to the available geological map, the reservoir size of Lacq is about $10 \mathrm{~km}$ in EW and $5 \mathrm{~km}$ in NS direction (Segall, 1992; Bardainne et al., 2008). Our epicenter location is rather around the northern bound of the reservoir (Figure 16). We are then interested in the stress field, which may have led to this earthquake. For this purpose, we carry out a simple elastic calculation without accounting for any complex behavior from the reservoir. Let us assume a vertical compaction of $1 \mathrm{~cm}$ along an elliptical horizontal interface $(10 \mathrm{~km} \times 6 \mathrm{~km})$ at $5 \mathrm{~km}$ depth and then calculate the displacement and stress field at $4 \mathrm{~km}$ depth. This setting can be calculated in a homogeneous, semi-infinite elastic medium (Okada, 1985, 1992). Figure 17 shows the calculation at $4 \mathrm{~km}$ depth, for which our solution has the minimum residual. Stress field is calculated for both possible solutions of the focal mechanism, (strike, dip, rake) $=\left(66.3^{\circ}, 32.0^{\circ},-114.6^{\circ}\right)$ and $\left(274.7^{\circ}, 61.2^{\circ},-75.4^{\circ}\right)$. The Coulomb stress change $\Delta C C F$ is defined as 


$$
\Delta C F F=\Delta \tau-\mu \times \Delta \sigma_{n}
$$

where $\Delta \tau$ and $\Delta \sigma_{n}$ (positive is taken for compression) are the shear and normal stress changes, respectively (e.g. King et al., 1994). Although the vertical displacement is simply symmetric (Figure 17A), the stress field has a variation from negative to positive values (Figure 17B-D). The amplitudes of the source parameters (dimension and compaction) are indicative, thus so is the obtained stress level. We do not aim to discuss the absolute change of stress, but this simple calculation allows discussing the spatial pattern of $\triangle C C F$ due to the reservoir compaction and the earthquake localization we obtained. Both areas identified in the previous chapter corresponds roughly to the southern edge of the reservoir ( $5 \mathrm{~km}$ in the east and $3 \mathrm{~km}$ in the south from the elliptical reservoir) or in the northern part ( $4.5 \mathrm{~km}$ in the east and $9 \mathrm{~km}$ in the north). Stress change reduces very quickly with distance, such that the former position is influenced much more due to the reservoir deformation. Both positions could receive a positive change of $\triangle$ CFF. As both are located in the south and the north, respectively, the favorable fault solution is different; the south-dipping solution for the southern location and the north-dipping one for the north. This is consistent with the seismo-tectonic interpretation on the cross sections of Bardainne et al. (2008).

Table 1: Obtained source parameters for (a) the ML4.0 2nd September 2013 and (b) the ML3.5 20th February 2017 earthquakes. Misfit is normalized for the minimum value of each earthquake. The reference time for the event is supposed at 12:36:35 and 17:03:41, respectively.

(a)

\begin{tabular}{ccccccc}
\hline $\begin{array}{c}\text { Focal depth } \mathrm{z} \\
(\mathrm{km})\end{array}$ & $\mathrm{Mw}$ & $\mathrm{t}_{0}(\mathrm{~s})$ & Strike $\left(^{\circ}\right)$ & $\operatorname{Dip}\left({ }^{\circ}\right)$ & Rake $\left(^{\circ}\right)$ & Misfit \\
\hline 3.0 & 3.26 & 0.04 & 131.5 & 80.5 & -34.7 & 1.31 \\
4.0 & 3.25 & 0.33 & 263.56 & 35.4 & -90.3 & 1 \\
5.0 & 3.22 & 0.47 & 123.4 & 61.7 & -51.5 & 1.11 \\
6.0 & 3.13 & 0.65 & 43.4 & 74.3 & -176.6 & 1.35 \\
8.0 & 3.14 & 7.04 & 108.0 & 20.1 & -66.9 & 2.29 \\
\hline
\end{tabular}

(b)

\begin{tabular}{ccccccc}
\hline $\begin{array}{c}\text { Focal depth } \mathrm{z} \\
(\mathrm{km})\end{array}$ & $\mathrm{Mw}$ & $\mathrm{t}_{0}(\mathrm{~s})$ & Strike $\left(^{\circ}\right)$ & $\operatorname{Dip}\left({ }^{\circ}\right)$ & Rake $\left(^{\circ}\right)$ & Misfit \\
\hline 3.0 & 3.30 & 0.70 & 105.7 & 81.0 & 67.6 & 1.03 \\
5.0 & 3.23 & 1.04 & 7.8 & 34.9 & -169.6 & 1.00 \\
6.0 & 3.21 & 0.94 & 7.2 & 38.2 & -170.9 & 1
\end{tabular}




\section{Conclusion}

The source mechanism of the $M\left\llcorner 4.025^{\text {th }}\right.$ April 2016 Lacq, South-West France, earthquake is analyzed. The routinely obtained position shows its hypocenter position within the old gas reservoir. We first analyze its focal mechanism through regional seismograms recorded in a $50 \mathrm{~km}$ radius around the epicenter and obtain EW running normal faulting. The solution is stable enough from the regional data. However a forward modeling of ground motion to the nearby station URDF does not explain the observation. We then look for the best epicenter position by performing wave propagation simulations. We constrain the potential source area using spatial distribution of Peak Ground Velocity (PGV). This indicates that the epicenter position is preferable a few to several $\mathrm{km}$ away to the north or south direction with respect to station URDF. The particle motions become also consistent with the observation. From the first movement of the ground motion, the epicenter position in the north from URDF is preferable, indicating the north-eastern edge of the Lacq reservoir. This is more consistent with the induced seismicity migration to the north and the northeast of the Lacq gas field by Bardainne et al. (2008). It is shown here that a single nearby station data allows estimating better the source characteristics according to the prior information (e.g. routinely obtained earthquake location) if using the full waveforms, and an engineering factor such as PGV also facilitates the calibration. The final solution shows a moment magnitude of Mw3.9 and the focal depth of $4 \mathrm{~km}$ corresponding in the crust above the reservoir. This position is consistent with the Coulomb stress change pattern due to a compaction at $5 \mathrm{~km}$ depth in the curst. Therefore, this earthquake can be interpreted as a relaxation of the shallow crust due to a deeper reservoir compaction. The insight from our seismological and mechanical analyses will be useful for improving local and regional seismic hazard analysis. This paper shows the ability of the seismological study using regional network, but for further studies, any local monitoring network would be required even after the definitive closure of the gas field.

\section{Data}

The seismological data (RESIF: Réseau sismologique et géodésique français; http://www.resif.fr/ ) used in this study are available from ORFEUS-EIDA data portal (http://www.orfeus-eu.org/data/eida/index.html) together with earthquake information provided by 
EMSC (Euro-Mediterranean Seismological Centre, http://www.emsc-csem.org ). The earthquake information in Rénass catalogue is available from http://renass.unistra.fr/. Map (Figure 16) is used on Google Map (http://maps.google.fr). The information in GAUL library used in our inversion is available from http://gaul.sourceforge.net/. The Coulomb stress is calculated using DC3D code (Okada, 1992), available from http://www.bosai.go.jp/study/application/dc3d/DC3Dhtml E.html.

\section{Acknowledgments}

This study has been funded by internal research \& development fund from BRGM. The calculation of Green function was carried out at French national supercomputing center (GENCI/CINES) under the grants c2016-046700 (2016), A0010406700 (2017) and A0030406700 (2017-18). We thank two anonymous reviewers for their comments, which improved our manuscript.

\section{References}

Aochi, H., T. Le Guenan, and A. Burnol, On estimation of seismic risk with respect to development of subsurface exploitation strategies for energy purpose, Petrol. Geosci., doi:10.1144/petgeo2016065, 2016.

Aochi, H., A. Ducellier, F. Dupros, M. Delatre, T. Ulrich, F. De Martin and M. Yoshimi, Finite difference simulations of seismic wave propagation for the 2007 Chuetsu-Oki earthquake : Validity of models and reliable input ground motion in the near-field, Pageoph, 170, 43-64, doi:10.1007/s00024-0110429-5, 2013a.

Aochi, H., T. Ulrich, A. Ducellier, F. Dupros, D. Michea, Finite difference simulations of seismic wave propagation for understanding earthquake physics and predicting ground motions: Advances and challenges, J. Phys: Conf. Ser., 454, 012010, doi: 10.1088/1742-6596/454/1/012010, 2013b.

Bardainne, T., Etude de la sismicité de Lacq et analyse des formes d'ondes par décomposition en chirplets, PhD thesis, University of Pau, France, 2005.

Bardainne, T., N. Dubos-Sallée, G. Sénéchal, P. Gaillot and H. Perroud, Analysis of the induced seismicity of the Lacq gas field (Southwestern France) and model of deformation, Geophys. J. Int., 172, 11511162, doi:10.1111/j.1365-246X.2007.03705.x, 2008.

Battaglia, J. and K. Aki, Location of seismic events and eruptive fissures on the Piton de la Fournaise volcano using seismic amplitudes, J. Geophys. Res., 108, 2364, doi:10.1029/2002JB002193, 2003. 
Bommer, J. J., S. Oates, J. M. Cepeda, C. Lindholm, J. Bird, R. Torres, G. Marroquin and J. Rivas, Control of hazard due to seismicity induced by a hot fractured rock geothermal project, Eng. Geol., 83, 287-306, doi:10.1016/j.enggeo.2005.11.002, 2006.

Bouchon, M., A simple method to calculate Green's functions for elastic layered media, Bull. Seism. Soc. Am., 71, 959-971, 1981.

Cara, M. et al. (38 co-authors), SI-Hex: a new catalogue of instrumental seismicity for metropolitan France, Bull. Soc. Géol. France, 2015, 186, 3-19, 2015.

Collino, F. and C. Tsogka, Application of the perfectly matched absorbing layer model to the linear elastodynamic problem in anisotropic heterogeneous media, Geophysics, 66, 294-307, 2001.

Dominique, P., Microseismicity in post mining context - The coal basin of Gardanne (Fuveau, Bouches du Rhone, Provence, Journées Nationales de Géotechniques et de Géologie de l'Ingénieur, Nancy, France, 2016. (extended abstract in French with English abstract)

Douglas, J., H. Aochi, P. Suhadolc and G. Costa, The importance of crustal structure in explaining the observed uncertainties in ground motion estimation, Bull. Earthquake Eng., 5, 17-26, 2007.

Dreger, D. S., and D. V. Helmberger, Determination of source parameters at regional distances with single station or sparse network data. J. Geophys. Res. 98, 8107-8125, 1993.

Goldberg, D., Genetic Algorithms in Search, Optimization, and Machine Learning, Addison-Wesley Professional, ISBN 978-0201157673, 1989.

Grasso, J. R. and G. Wittlinger, Ten years of seismic monitoring over a gas field, Bull. Seism. Soc. Am., 80(2), 450-473, 1990.

Holland, J. H., Adaptation in Natural and Artificial Systems. University of Michigan Press, 1975.

Hough, S. E., Shaking from injection-induced earthquakes in the Central and Eastern United States, Bull. Seism. Soc. Am., 104, 2619-2626, doi:10.1785/0120140099, 2014.

Ide, S. and H. Aochi, Earthquakes as multiscale dynamic ruptures with heterogeneous fracture surface energy, J. Geophys. Res., 110, B11303, doi:10.1029/2004JB003591

King, G. C. P., R. S. Stein and J. Lin, Static stress changes and the triggering of earthquakes, Bull. Seism. Soc. Am., 84, 935-953, 1994.

Kubo, A., E. Fukuyama, H. Kawai and K. Nonomura, NIED seismic moment tensor catalogue for regional earthquakes around Japan: quality test and application, Tectonophysics, 356, 23-48, 2002. 
Okada, Y., Surface deformation due to shear and tensile faults in a half-space, Bull. Seism. Soc. Am., 75, 1435-1454, 1985.

Okada, Y., Internal deformation due to shear and tensile faults in a half-space, Bull. Seism. Soc. Am., 82, 1018-1040, 1992.

Segall, P., Induced stresses due to fluid extraction from axisymmetric reservoirs, Pageoph, 139, 535560, 1992.

Segall, P., J.-R. Grasso and A. Mossop, Poroelastic stressing and induced seismicity near the Lacq gas field, southwestern France, J. Geophys. Res., 99 15423-15438, 1994.

Souriau, A. and M. Granet, A tomographic study of the lithosphere beneath the Pyrenees from local and teleseismic data, J. Geophys. Res., 100(B9), 18117-18134, 1995.

Ulrich, T. and H. Aochi, Rapidness and robustness of finite source inversion from elliptical patches method using continuous GPS and acceleration data: 2011 Mw9.0 Tohoku earthquake, Pageoph, 172, 3439-3453, doi:10.1007/s00024-014-0857-0, 2015.

Wells, D. L. and K. J. Coppersmith, New empirical relationships among magnitude, rupture length, rupture width, rupture area, and surface displacement, Bull. Seism. Soc. Am., 84, 974-1002, 1994. 


\section{Appendix}

This appendix shows the detailed analysis for the 2013/09/02 ML4.0 earthquake mentioned in the discussion section. We apply the same procedure as in the text for the 2016/04/25 ML4.0 earthquake. Figure A1 shows the waveform fit for the focal mechanism inversion, supposing $4.0 \mathrm{~km}$ focal depth. There are only two stations ATE and PYLO available at epicenteral distance of about 50 $\mathrm{km}$. The station URDF (a few kilometers from the supposed epicenter) is not used in the inversion. Figure A2 shows the PGV map from the nearfield ground motion using the obtained focal mechanism. From the observation, the PGV in EW, NS and UD is $0.008,0.048$, and $0.019 \mathrm{~cm} / \mathrm{s}$, respectively. Figure A3 represents the grid search of better positions of source-receiver. The NS movement is dominant and this information limits the probable area. The PGV is much smaller than the 2016/04/25 earthquake and briefly consistent with our simulation of Mw3.25 source. The position \#00142, namely the epicenter located in the south-west by a few kilometers, represents the minimum misfit and consistent with the polarity of the particle motions. 


\section{Figure captions}

Figure 1: (A) Map around the 2016/04/25 ML4.0 Lacq earthquake in the Pyrenees region in the SouthWestern France. The epicenter position is marked by star. The stations available from ORFEUS/EIDA are shown by triangles. The seismicity is plotted for the period 1970-2009 from SI-Hex / BCSF-LDG catalogue (Cara et al., 2015). (B) Seismicity in function of time for an area of longitude between $0.8^{\circ} \mathrm{W}$ and $0.3^{\circ} \mathrm{W}$ and of latitude between $43.25^{\circ} \mathrm{N}$ and $43.75^{\circ} \mathrm{N}$ from the same catalogue (magnitude in $\mathrm{Mw}$ ). The known biggest earthquake of ML4.2 1978/09/18 event is plotted by cross (Grasso et al., 1990). Three recent felt earthquakes of 2013/09/02, 2016/04/25 and 2017/02/20 are plotted (magnitude in ML). The period after 2010 is shaded since the SI-Hex/BCSF-LDG catalogue ends by 2009.

Figure 2: East-west components of ground motions in velocity. The signals are aligned at 4:43:40 UT, and normalized by its maximum amplitude (in $\mathrm{cm} / \mathrm{s})$. Station locations are shown in Figure 1.

Figure 3: 1D profile of seismic wave velocities used in this moment tensor inversions of this study.

Figure 4: The obtained solution of focal mechanism for each focal depth. Residual is normalized by the minimum residual (focal depth $=3 \mathrm{~km}$ ). The number shows moment magnitude obtained.

Figure 5: GA convergence for the focal depth of $z=3 \mathrm{~km}$. Population number starts from 100 at the first generation and increases up to 186 at the $21^{\text {st }}$ generation. Top panel shows the convergence of residual during the whole seeds. Bottom panels show the convergence of five model parameters with the generation. All the seeds are plotted by grey small points, and the best solutions of each generation are emphasized with large black symbols.

Figure 6: Waveform fitting between the observation and synthetics at three stations for the focal depth of $z=3 \mathrm{~km}$. Synthetics represent the final solution after the $21^{\text {st }}$ generation and the thin grey lines show the intermediate solutions (the best solution at each generation, shown in Figure 5). The seismograms in velocity are filtered between 16-32 s. The origin time is then $30+t_{0}(s)$. The residuals are calculated between 10 and 70 seconds. 
Figure 7: Comparison of waveforms at URDF for depths of $z=2,3$ and $8 \mathrm{~km}$. This station is not used in the inversions. The calculation and illustrations are in the same way as Figure 6.

Figure 8: 1D structure model used for near-field ground motion simulations.

Figure 9: Comparison of ground motion at URDF between the observation and the simulation for the focal mechanism obtained at $3 \mathrm{~km}$ depth. (A) Positions of the source (Rénass) and receiver URDF. (B) Three component ground motions filtered between 0.05 and $1 \mathrm{~Hz}$. (C) Horizontal particle motions for the time 0 to 5 seconds.

Figure 10: PGV (Peakg Ground Velocity) of each component of the ground motions simulated for the focal mechanism obtained at $3 \mathrm{~km}$ depth. The PGV is calculated after a filter upto $1 \mathrm{~Hz}$. In the below panels, the area is restricted for PGV(NS)/PGV(EW) $>3$ and $0.043 \mathrm{~cm} / \mathrm{s}<P G V(N S)<0.387 \mathrm{~cm} / \mathrm{s}$. The source is put at the origin of the figure. Small triangles show the synthetic receiver positions.

Figure 11: Spatial distribution of misfits between the observation and synthetics for the area selected in Figure 10. The three components and the NS component only are shown. The misfit is calculated during the 10 seconds after a filter between 0.02 to $1 \mathrm{~Hz}$ (see text).

Figure 12: The comparison of ground motions at receivers \#1249 (6 km away to the North) and at \#1196 (9 km away to the South). (A) The relative position of both receivers with respect to hypocenter. (B) Comparison of the waveforms in time series during 10 seconds (upper panel) and in particle motions during the first 5 seconds (bottom). A bandpass filtere between 0.05 and $1 \mathrm{~Hz}$ is applied. The waveforms are shifted on illustration. (C) Comparison of the waveforms in velocity and displacement for the NS component without filter.

Figure 13: The finally obtained focal mechanism solution for each focal depth. Residual is normalized by the minimum residual (focal depth $=4 \mathrm{~km}$ ). The number shows moment magnitude obtained. 
Figure 14: Earthquake scenarios A and B on a finite fault, simulated by Ide and Aochi (2005). The rupture time and final slip are shown for the two models. The slip direction is parallel to the horizontal axis. Moment magnitudes are 3.78 and 3.83, respectively. The star represents the initial point of earthquake rupture, and fixed to the hypocenter for the ground motion simulations.

Figure 15: The PGV maps of three components calculated for the two finite source models $A$ and $B$, shown in Figure 14. On the right, the area restricted by PGV(NS)/PGV(EW) $>3$ and $0.043 \mathrm{~cm} / \mathrm{s}<$ $P G V(N S)<0.387 \mathrm{~cm} / \mathrm{s}$ is shown for the dominant NS component. See also caption of Figure 13.

Figure 16: Obtained Localisation of the 2016 Lacq earthquake (ellipsoid), comparing to the routinely obtained solution (red circle) and station URDF (red rectangle). The dimension of the ellipsoid briefly corresponds to the area around the smallest residuals observed in Figures 4 and 15, namely $+-1.5 \mathrm{~km}$ in EW, $+-3.0 \mathrm{~km}$ in NS and +-1.5 km in depth. Map is adopted from Google Map (http://maps.google.fr). The mesh shows the top of the reservoir.

Figure 17: Displacement and stress field at $4 \mathrm{~km}$ depth due to a vertical compaction of $1 \mathrm{~cm}$, projected as broken elliptical area $(10 \mathrm{~km} \times 6 \mathrm{~km})$, at $5 \mathrm{~km}$ depth. Stress is calculated for the both possible solution of the focal mechanisms, (strike, dip, rake) $=\left(66.3^{\circ}, 32.0^{\circ},-114.6^{\circ}\right)$ and $\left(274.7^{\circ}, 61.2^{\circ},-75.42^{\circ}\right)$, respectively, as fault plane 1 and 2 . The two circles indicate briefly the two indicated areas of the earthquake. (A) Vertical displacement in cm, (B) shear stress in MPa to the rake direction, (C) normal stress in MPa and (D) $\triangle \mathrm{CFF}$ in MPa to the rake direction.

Figure A1: Waveform (ground velocity in $\mathrm{cm} / \mathrm{s}$ ) fitting between the observation and synthetics at three stations for the 2013/09/02 earthquake with focal depth of $z=4 \mathrm{~km}$. Synthetic (red curves) represent the final solution after the $21^{\text {st }}$ generation and the thin grey lines show the intermediate solutions. The seismograms in velocity are filtered between 16-32 s. The time 0 is taken at 12:36:35. The obtained source parameter is summarized in Table 1(a). 
Figure A2: PGV (Peak Ground Velocity) of each component of the ground motions simulated for the focal mechanism obtained at $4 \mathrm{~km}$ depth. The PGV is calculated after a filter upto $1 \mathrm{~Hz}$. The relative position of station URDF with respect to the supposed source position is shown. Small triangles show the synthetic receiver positions.

Figure A3: (a) Misfit between the observation and synthetics for the 10 seconds. The area is limited by $P G V(N S) / P G V(E W)>5$ and $0.016 \mathrm{~cm} / \mathrm{s}<P G V(N S)<0.143 \mathrm{~cm} / \mathrm{s}$. Initially supposed URDF station position is shown by green. Two local minimums are shown in red and green. (b) Comparison of the waveforms filtered between 0.02 and $1 \mathrm{~Hz}$. (c) Particle motion of the first 5 seconds. 
Figure 1:

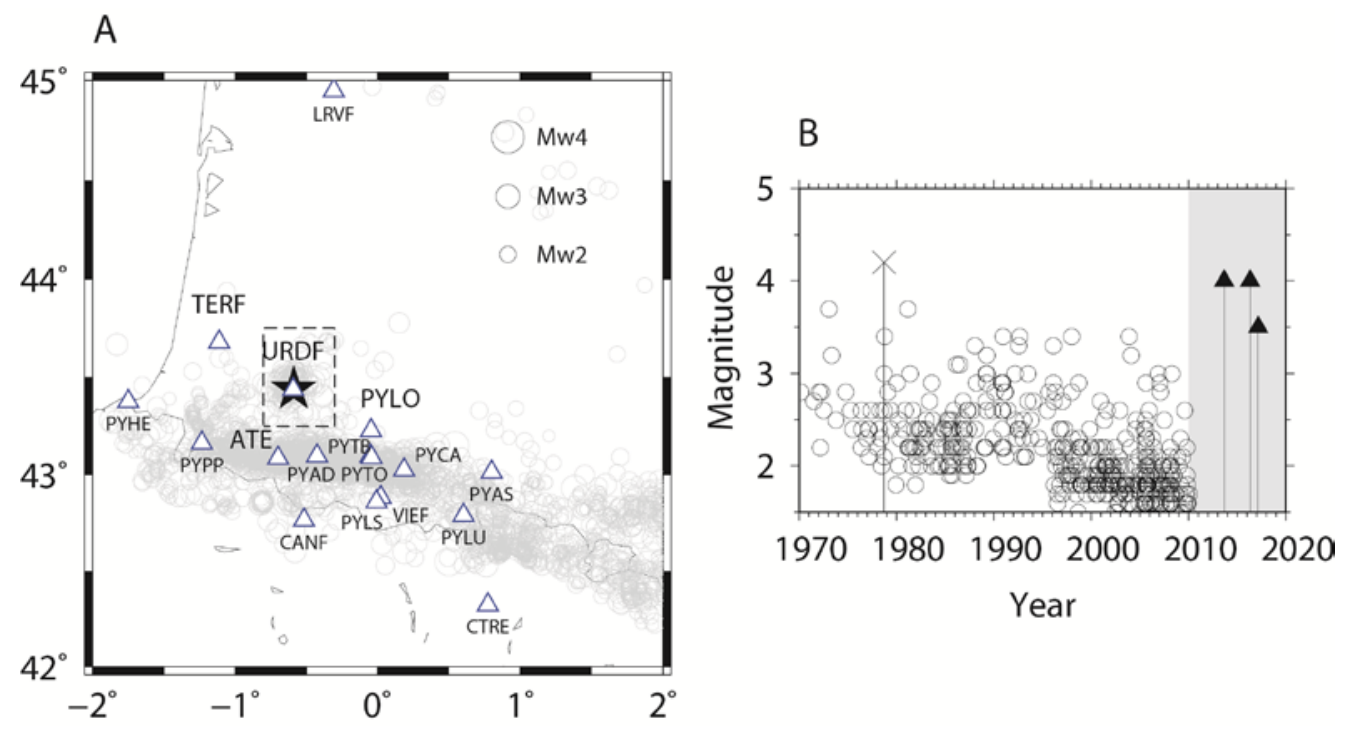


Figure2 :

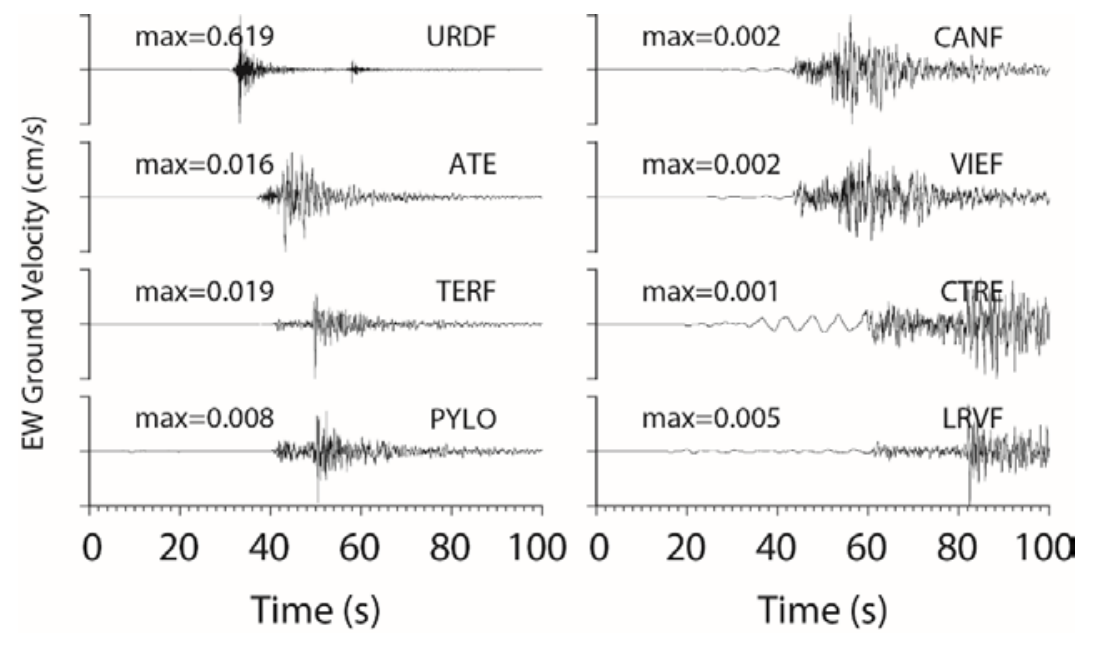


Figure3 :

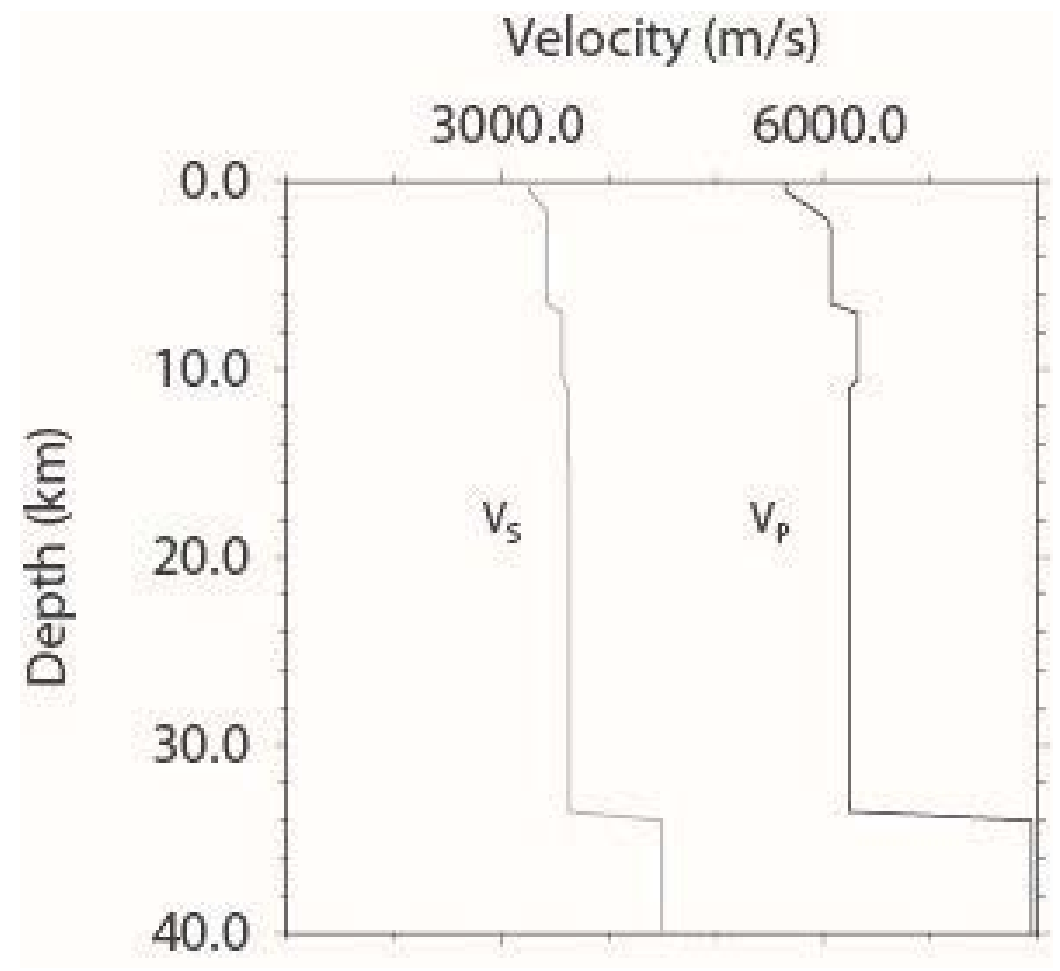


Figure4 :

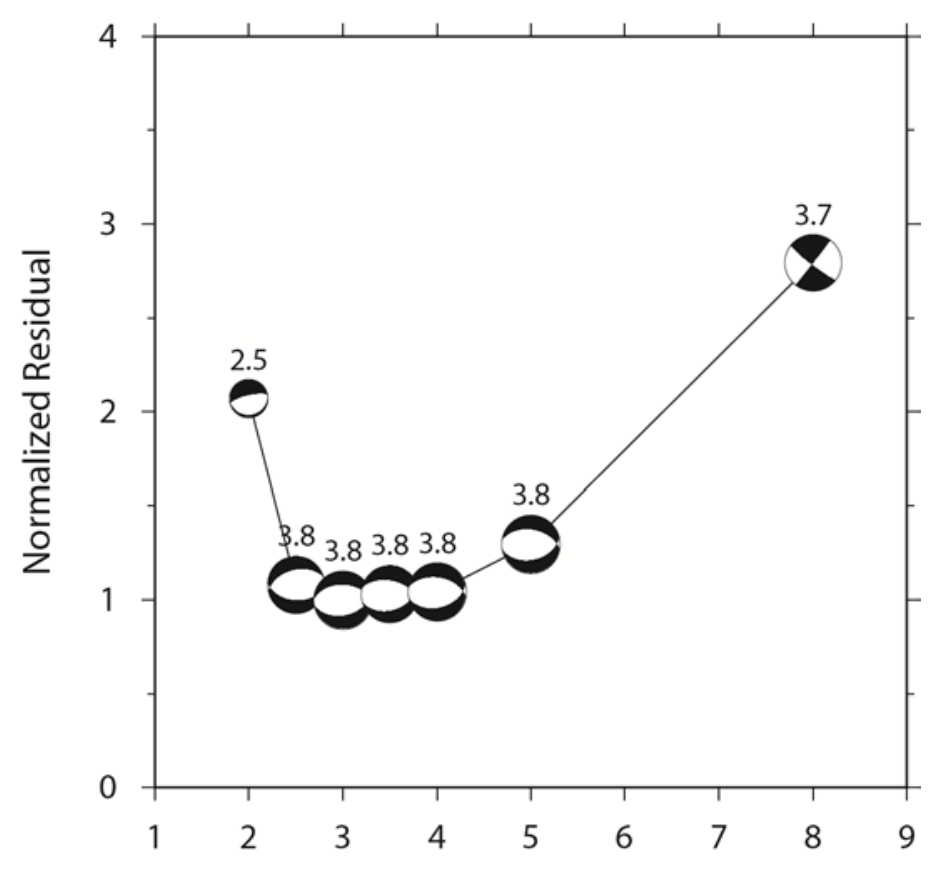

Focal Depth (km) 
Figure5 :
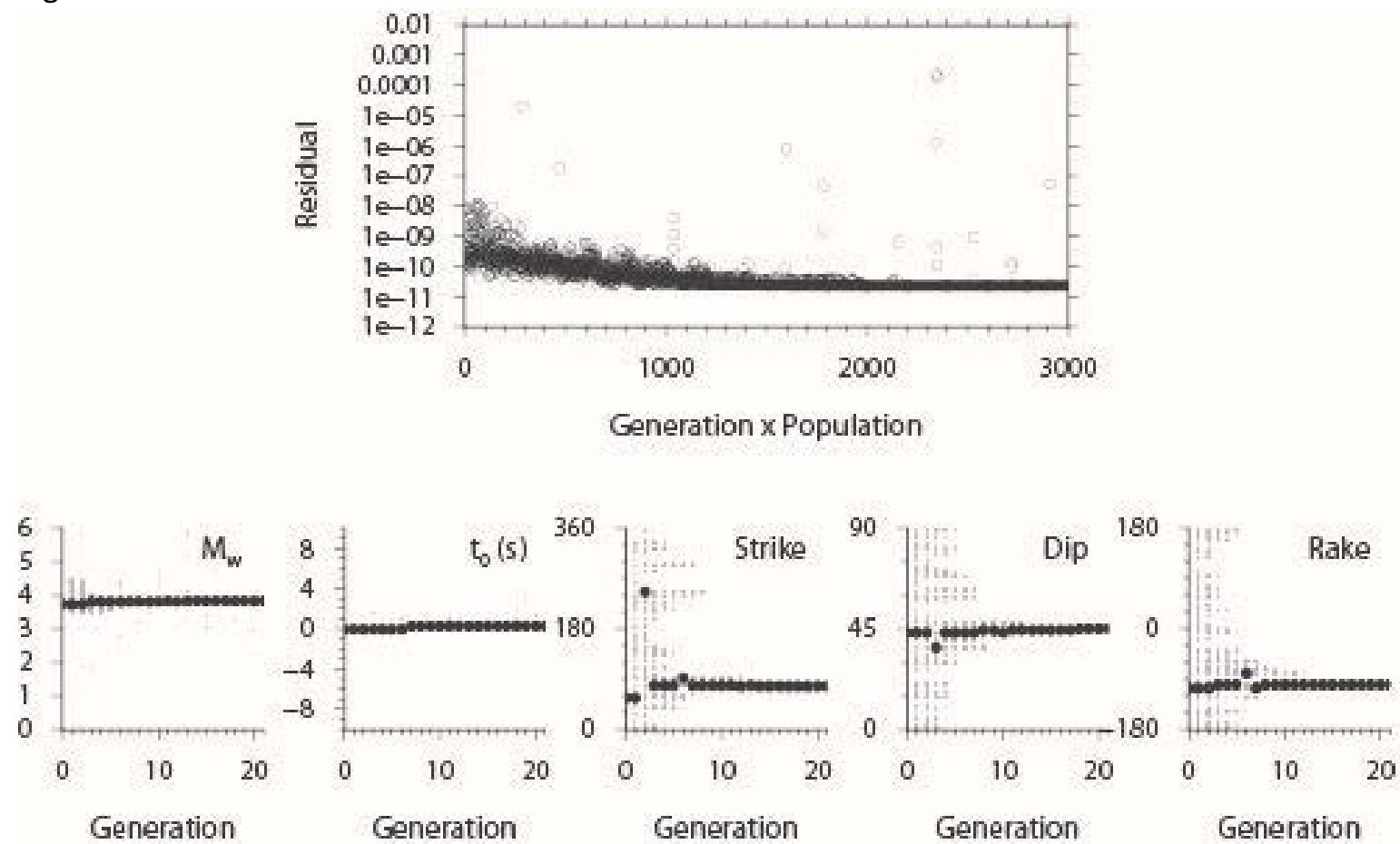
Figure 6 :

$\mathrm{z}=3 \mathrm{~km}$ : Ground Velocity in $\mathrm{cm} / \mathrm{s}$, filtered between $16-32 \mathrm{~s}$
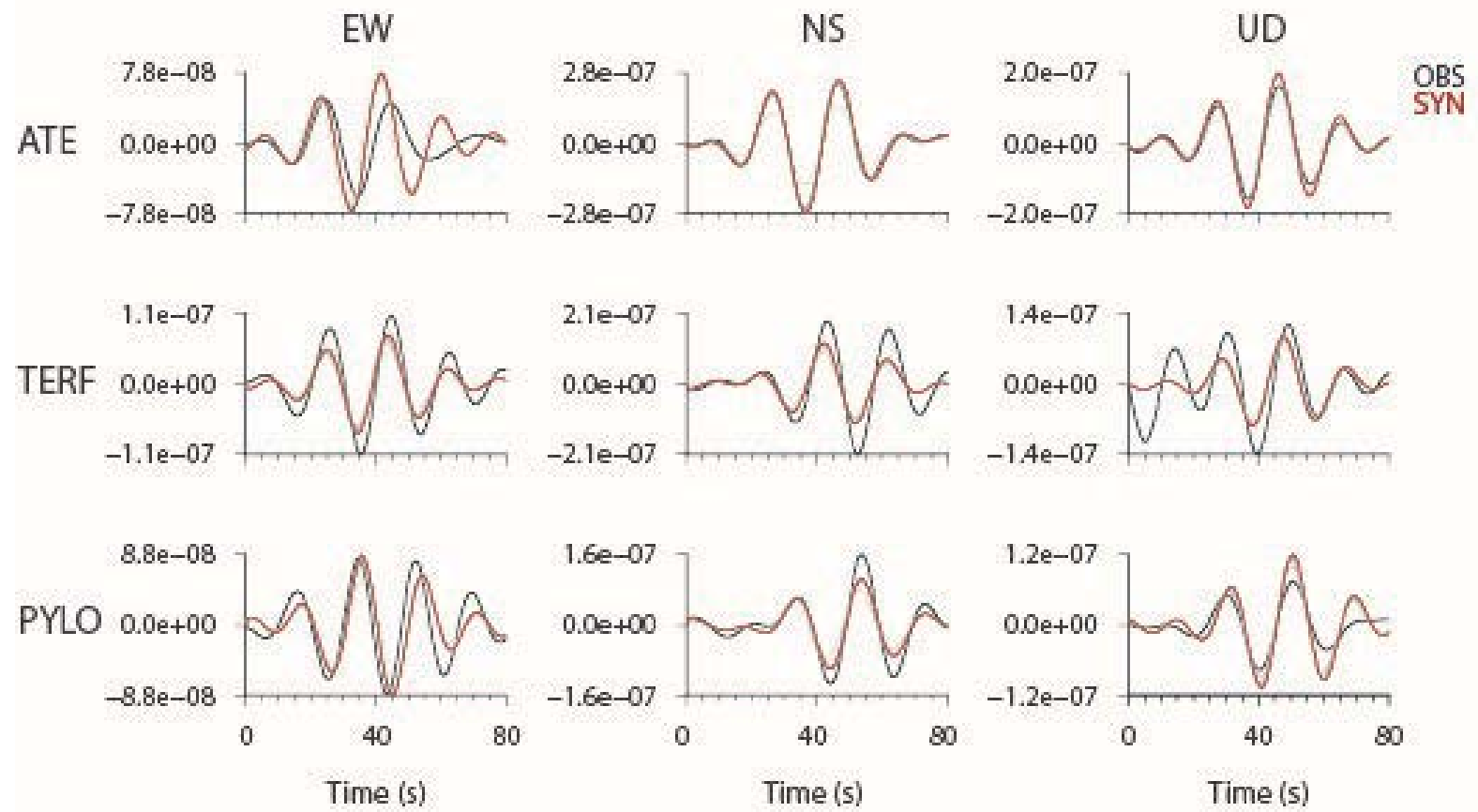
Figure 7 :

URDF: GroundVelocity in $\mathrm{cm} / \mathrm{s}$, filtered between $16-32 \mathrm{~s}$

$\mathrm{z}=2 \mathrm{~km} \quad \mathrm{EW}$

NS

UD
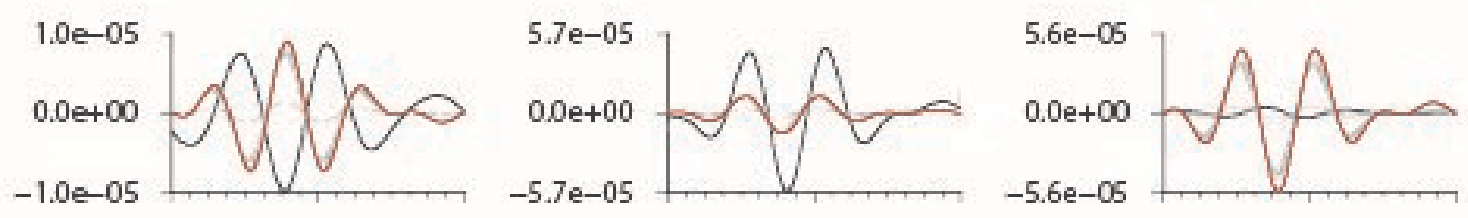

OBS

$\mathrm{z}=3 \mathrm{~km}$
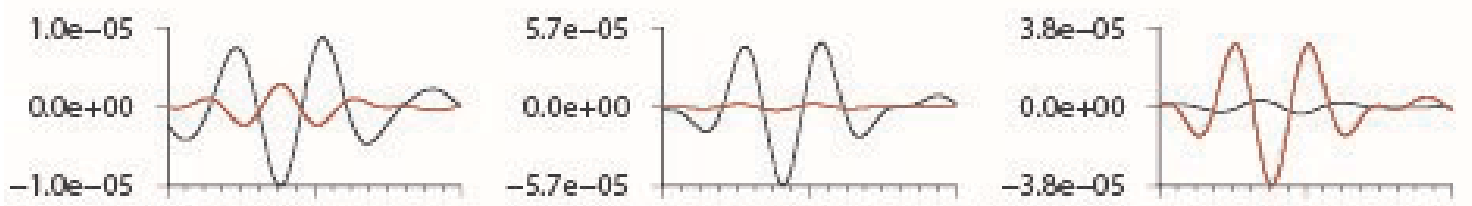

$\mathrm{z}=8 \mathrm{~km}$

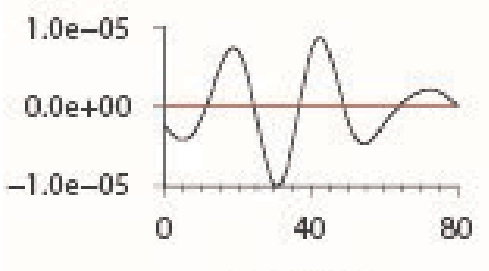

Time (s)
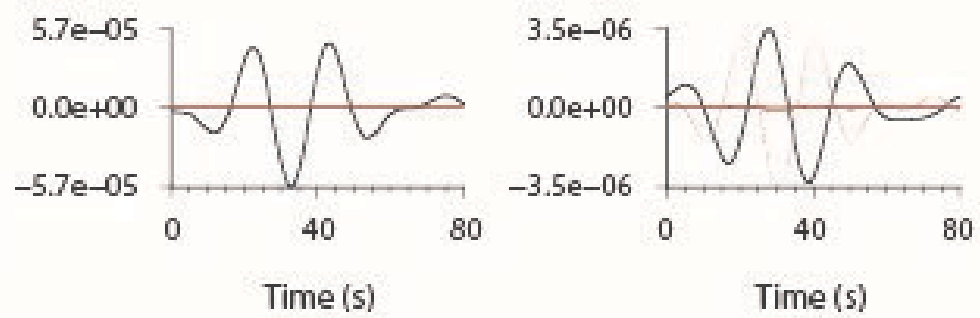
Figure 8 :

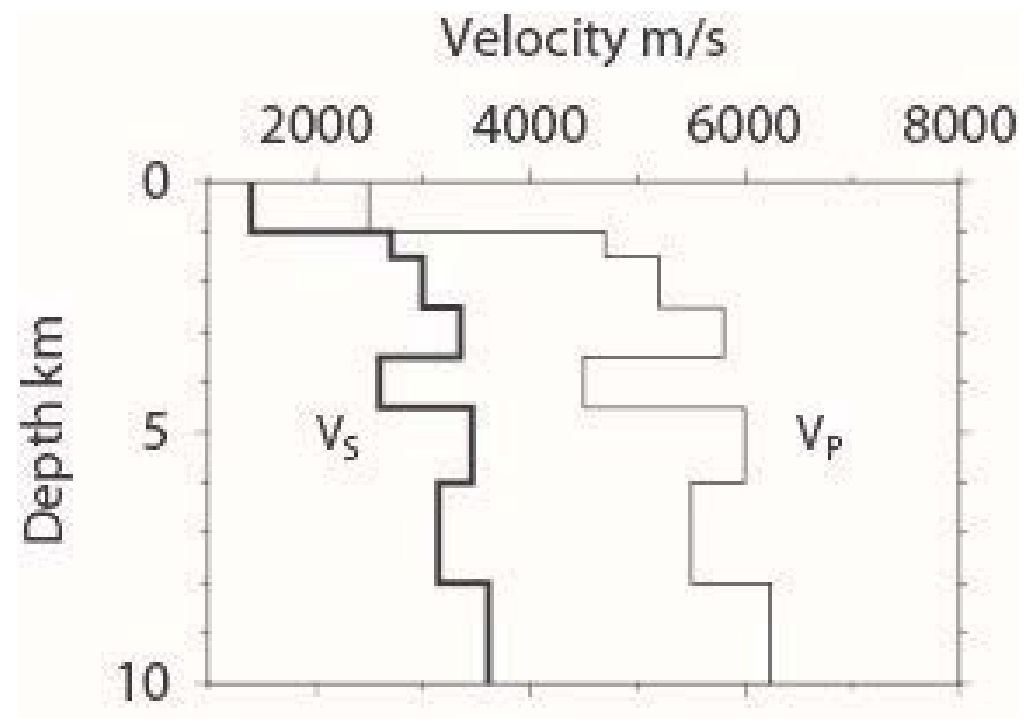


Figure 9 :
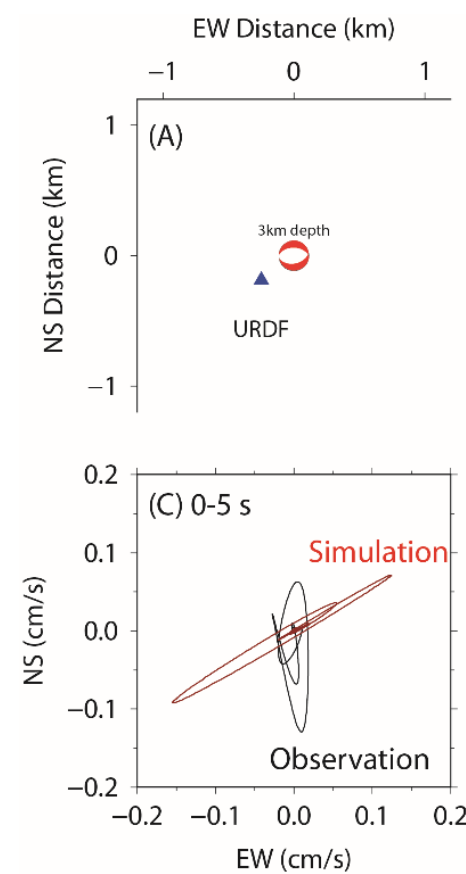

(B)

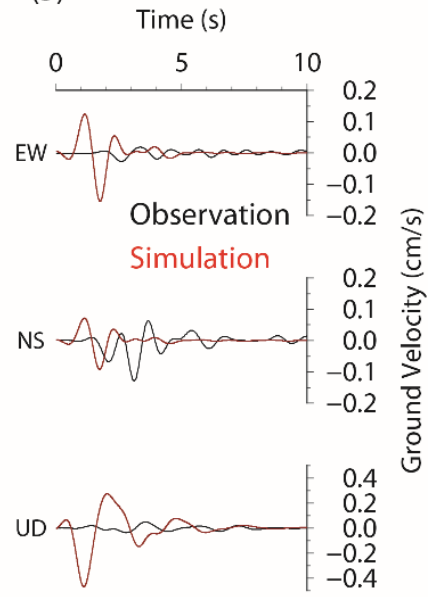


Figure 10 :
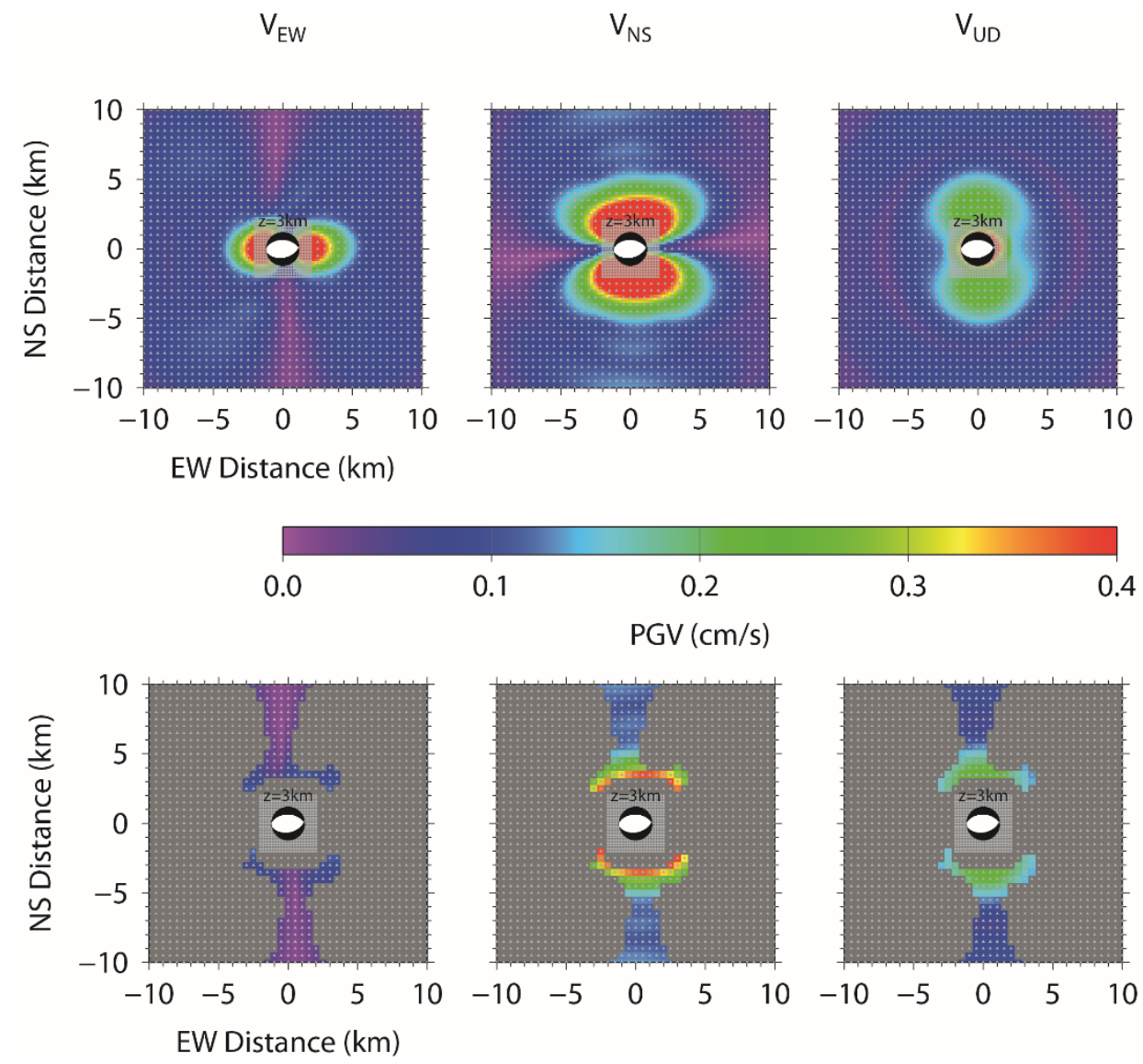
Figure 11 :

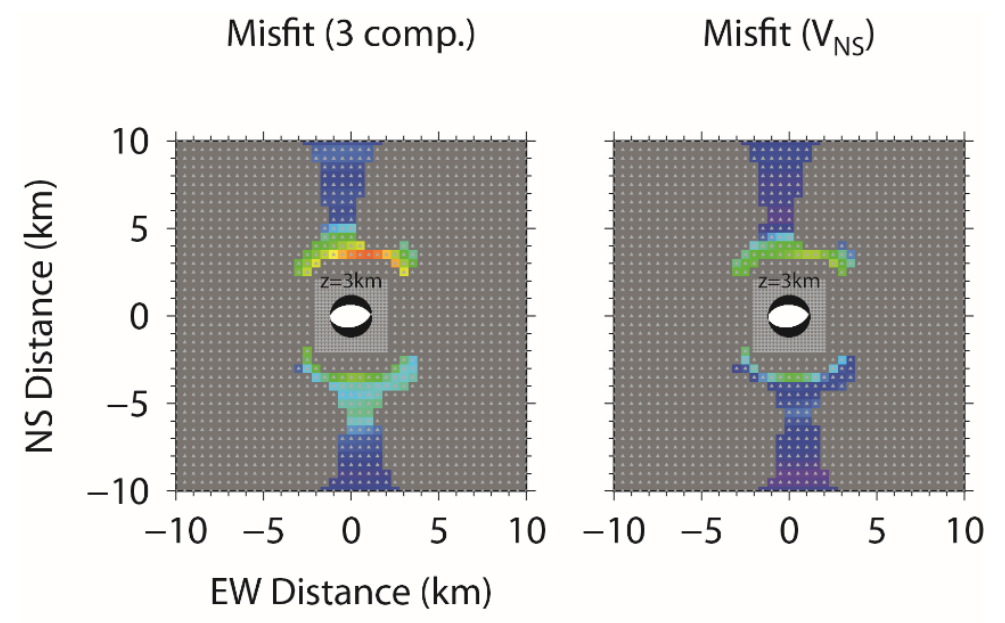

$$
\begin{array}{cccccc}
0.0000 & 0.0001 & 0.0002 & 0.0003 & 0.0004 & 0.0005 \\
\text { Misfit } & & &
\end{array}
$$


Figure 12 :

(B) Time (s)

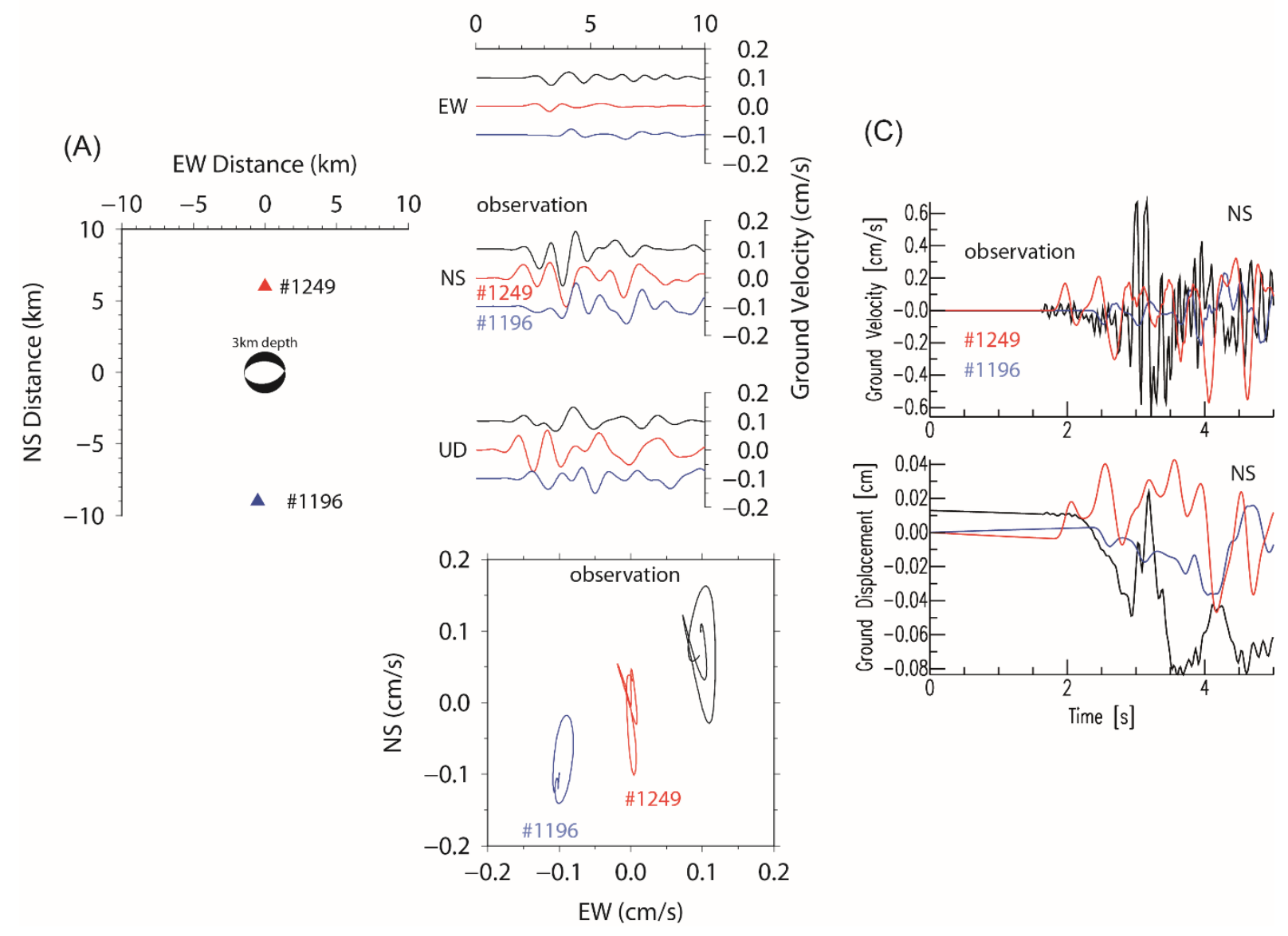


Figure 13 :

(m)

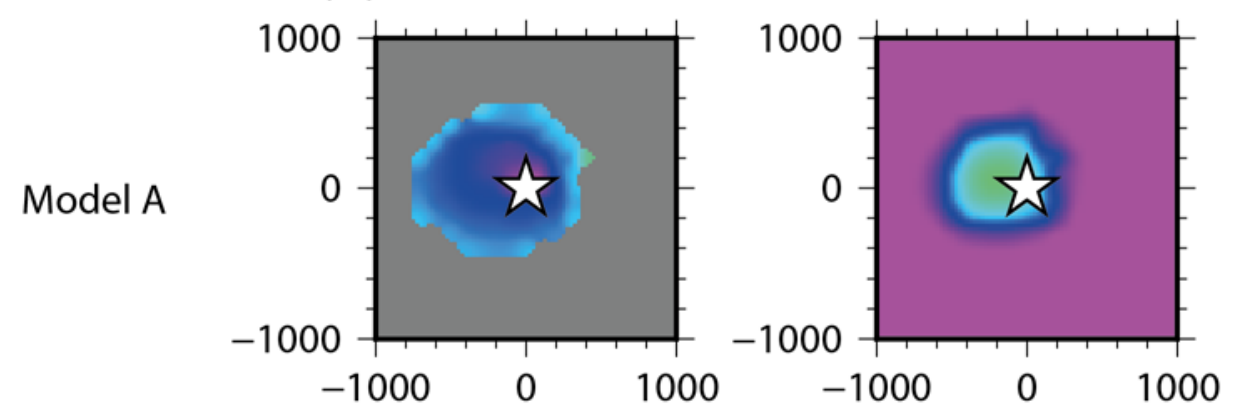

(m)

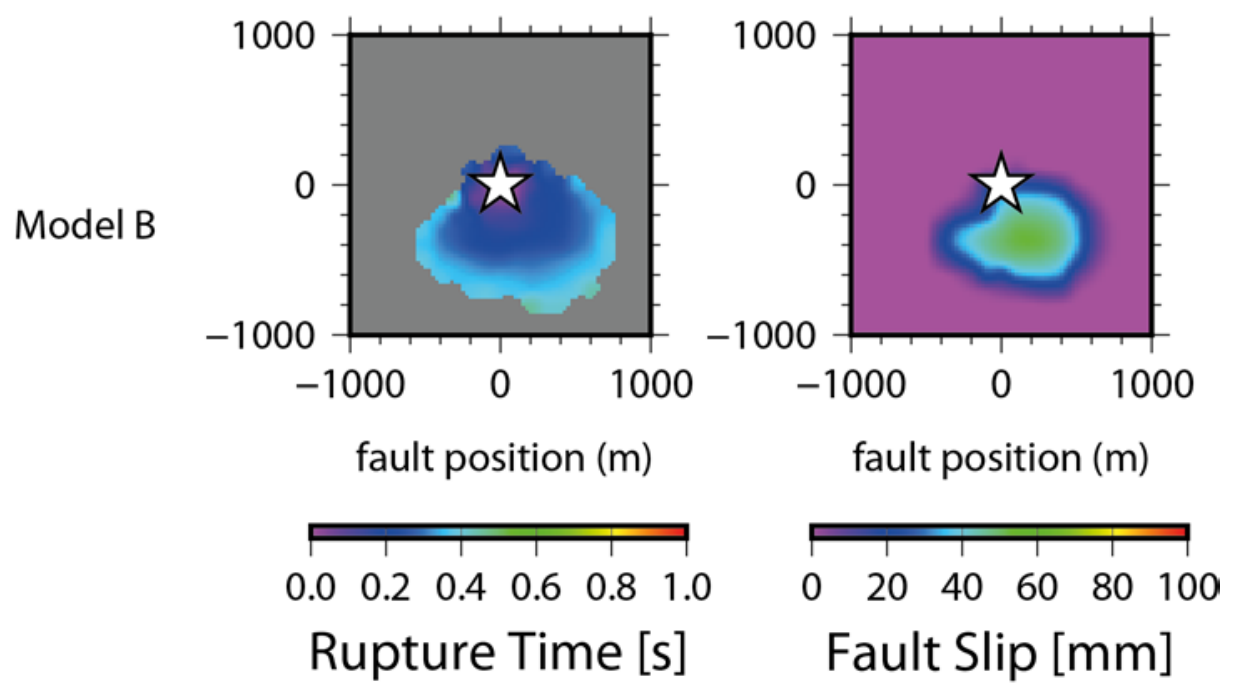


Figure 14 :
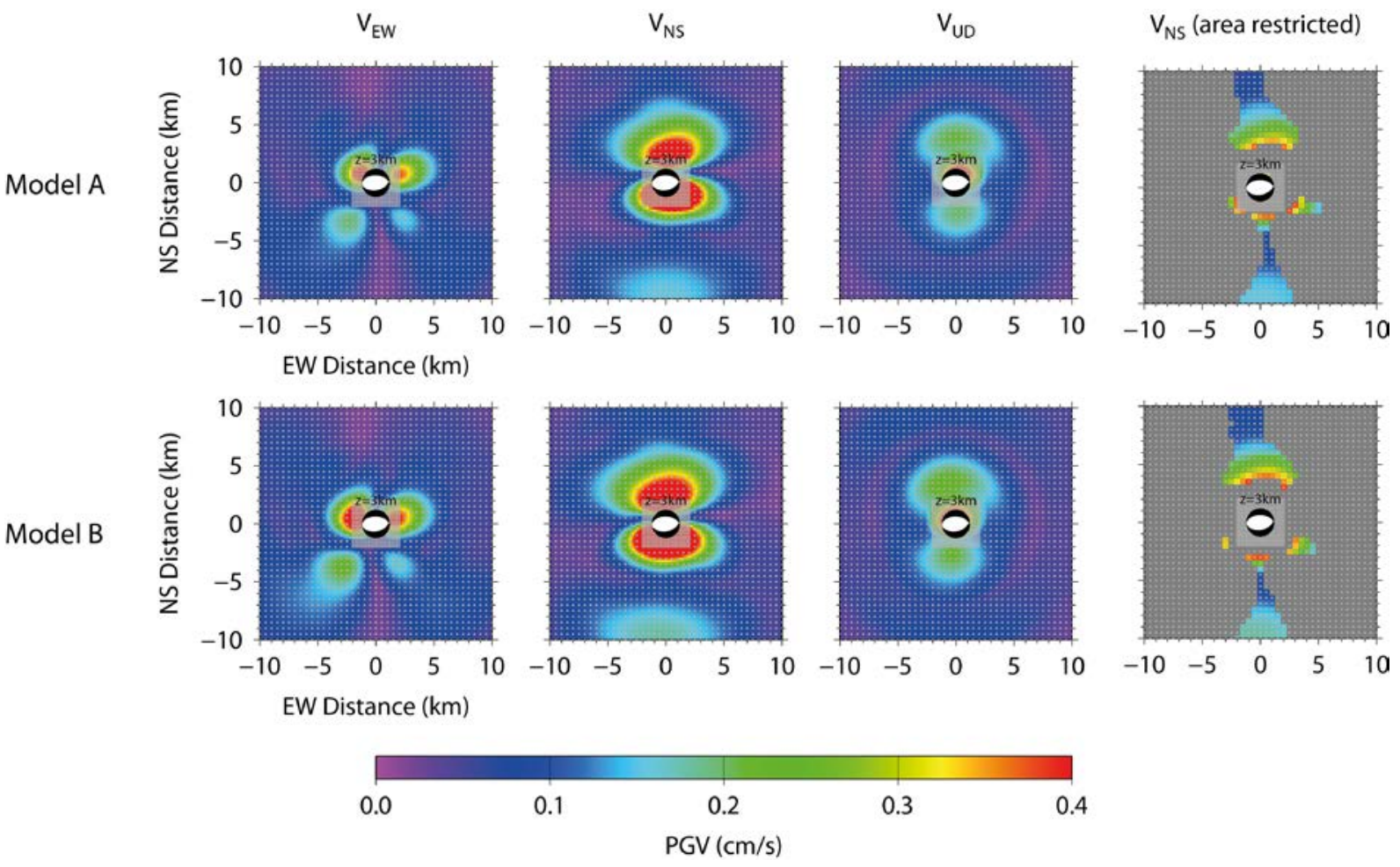
Figure 15 :

\section{6/04/25 ML4.0 LACQ EARTHQUAKE}

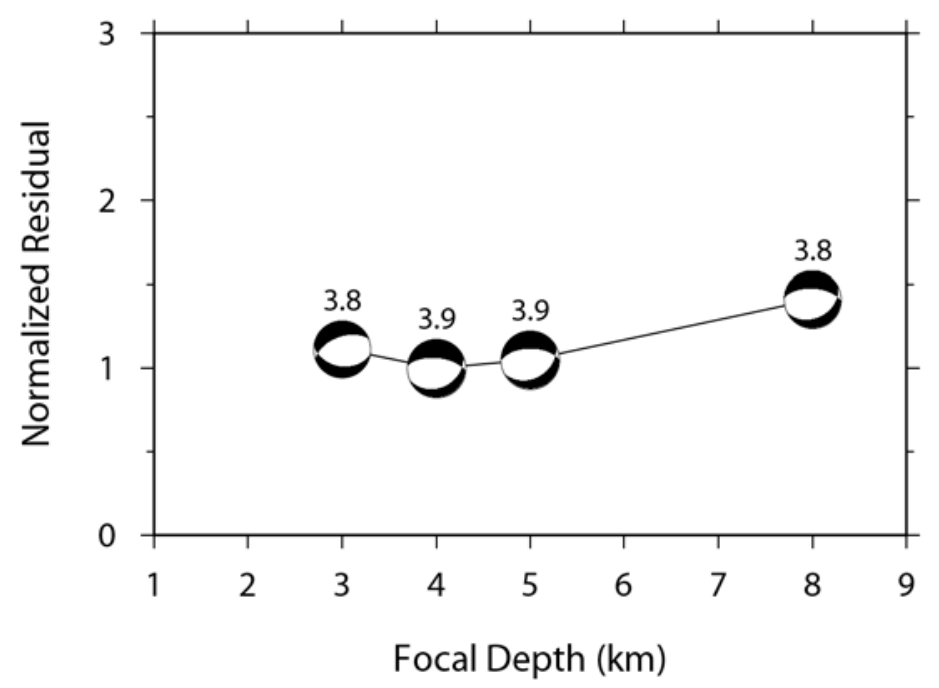


Figure 16 :

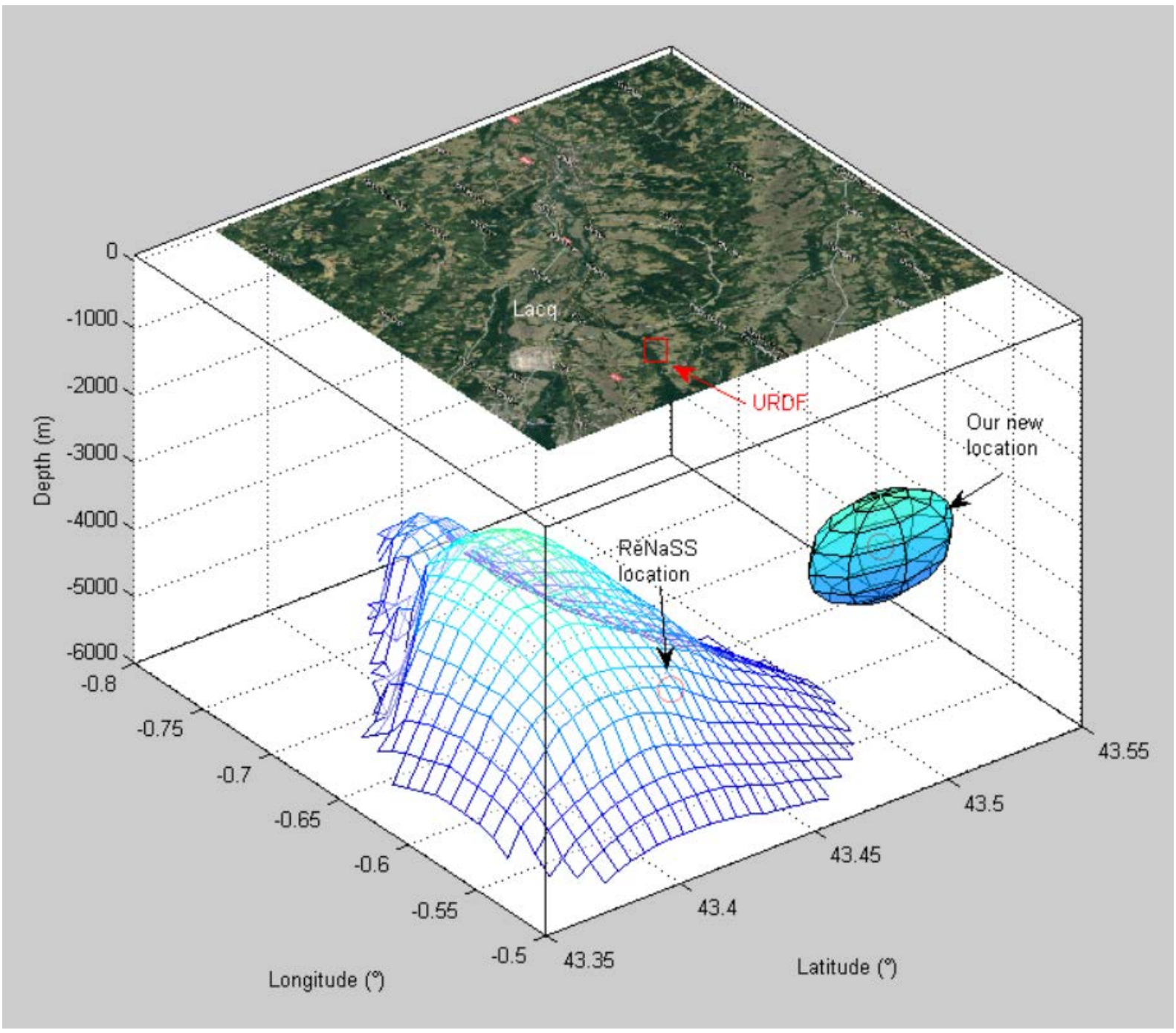


Figure 17 :

I. Fault Plane 1

(A) Vertical Disp.
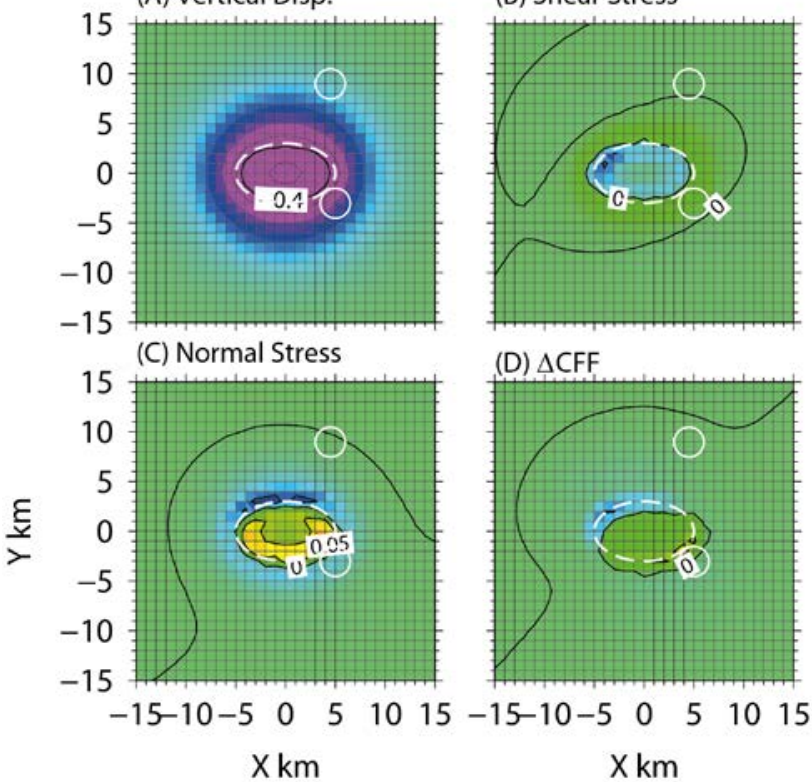

(B) Shear Stress

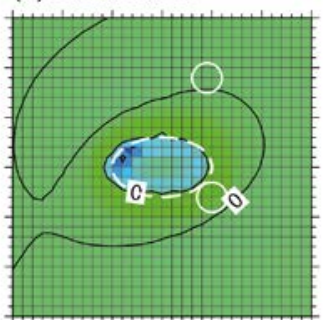

(D) $\triangle \mathrm{CFF}$
II. Fault Plane 2

(A) Vertical Disp.

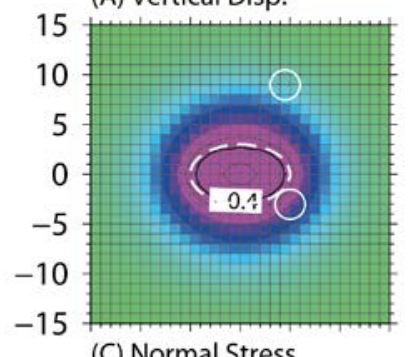

(C) Normal Stress

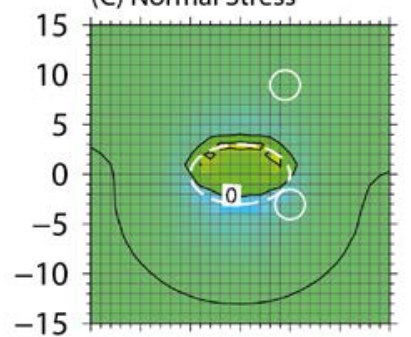

$\begin{array}{llllllllll}-15-10-5 & 0 & 5 & 10 & 15 & -15-10-5 & 0 & 5 & 10 & 15\end{array}$

$\mathrm{X} \mathrm{km}$
(B) Shear Stress

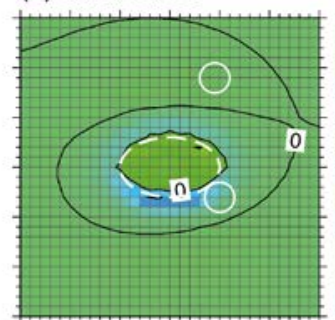

(D) $\triangle$ CFF

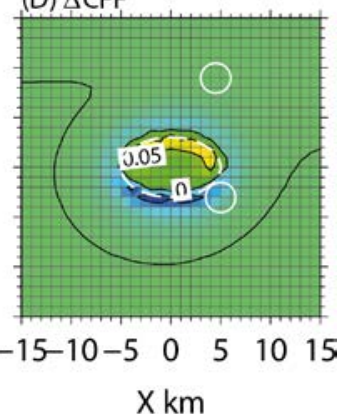


Figure A1 :
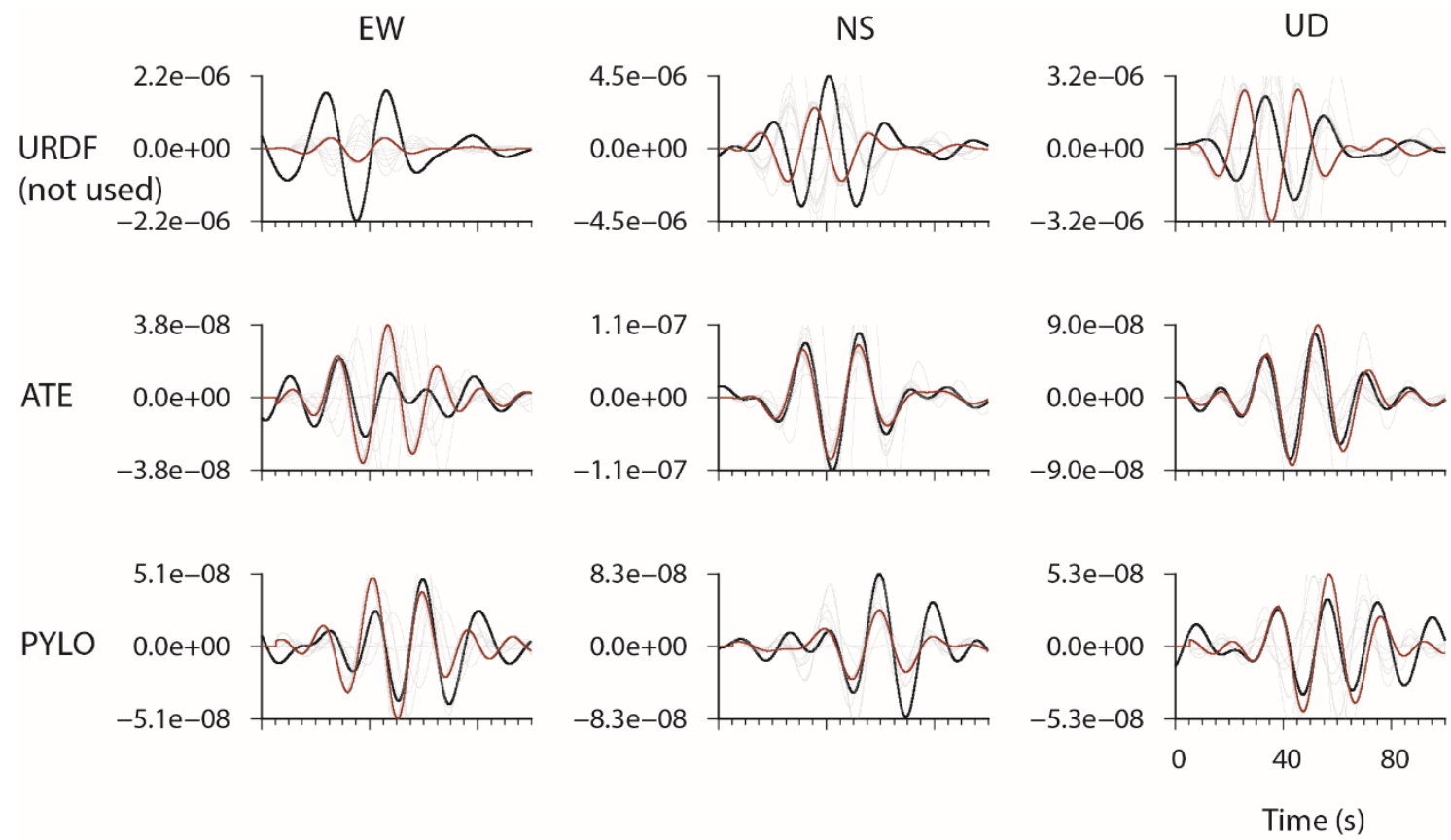
Figure A2 :

$$
\mathrm{V}_{\mathrm{EW}}
$$

$\mathrm{V}_{\mathrm{NS}}$

$V_{U D}$

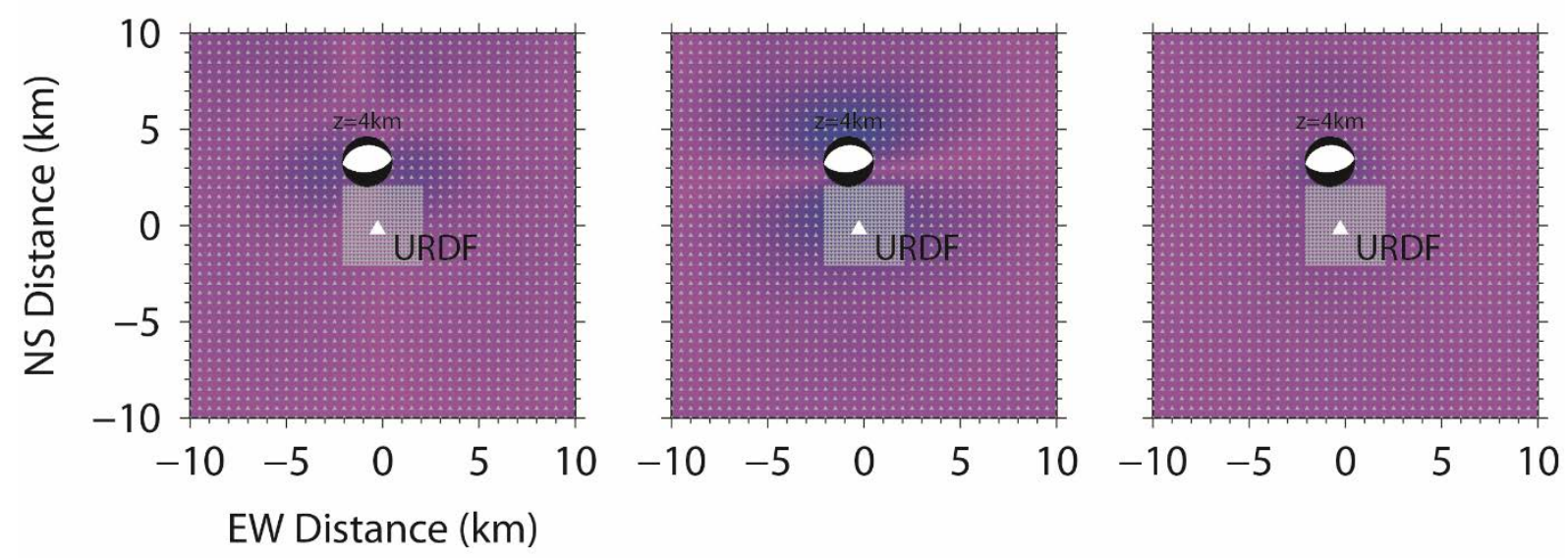

$\begin{array}{ccccc}0.0 & 0.1 & 0.2 & 0.3 & 0.4 \\ & & P G V(\mathrm{~cm} / \mathrm{s}) & & \end{array}$


Figure A3 :
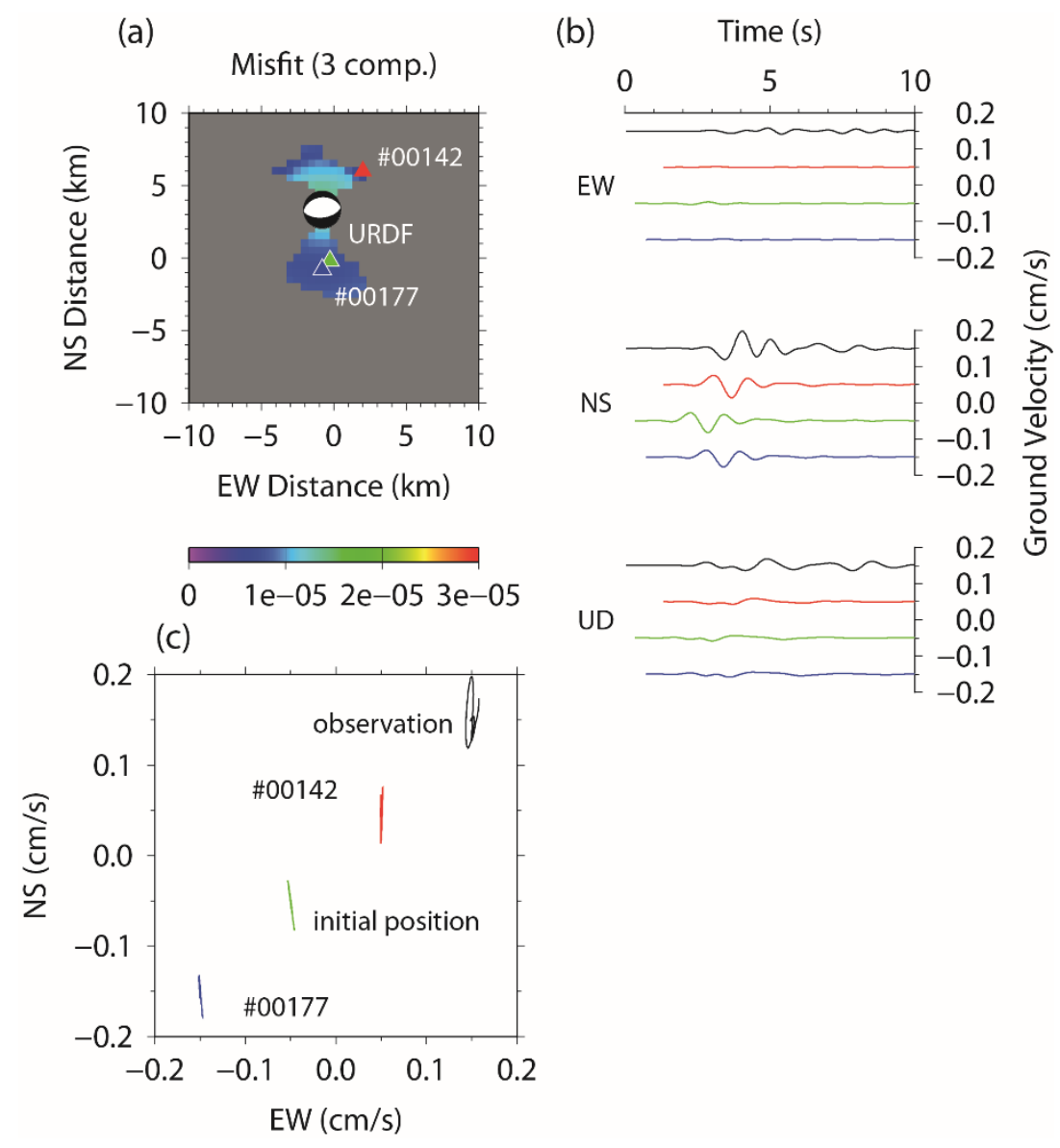